\title{
Camotlán: cómo nació un conflicto entre Jalisco y Nayarit
}

\author{
Beatriz Rojas \\ INL/INSTITUTO MORA
}

$\mathrm{L}$ a delimitación de colindancias entre paises siempre ha sido un asunto delicado. México tuvo guerra con Estados Unidos por este problema. Guatemala y México han tenido diferendos por la misma razón. Cuántas páginas pođríamos llenar, listándo los problemas internacionales suscitados por delimitación de fronteras.

Pero esto no nada más es asunto de la órbita internacional; en el interior de los estados este conflicto también es corriente. Concretamente, en México existen un buen número de diferendos entre no pocos estados, por la fijacion de sus limites. Aguascalientes tuvo problemas con Zacatecas. Éste con Durango y Jalisco con Nayarit, para no dar más ejemplos.

En las siguientes páginas pretendo seguir uno de estos conflictos, el suscitado entre Jalisco y Nayarit, que desde hace casi cien años enfrenta a estos estados en la disputa por un territorio enclavado en la Sierra Madre, en la zona que ahora se conoce como el Cañón de Camotlán.

\section{El Cañón de Camơtlán y sus POBLADORES}

Por lo que sabemos, al momento de la conquista, esta parte de la Sierra Madre, localizada entre los $105 \mathrm{y}$ 104 grados de longitud $y$ en una latitud norte que va de $21^{\circ}$ a $22^{\circ}$, estaba habitada por diferentes grupos étnicos emparentados entre sí, entre los cuales se encontraban: los visuritas o más comúnmente llamados huicino- 


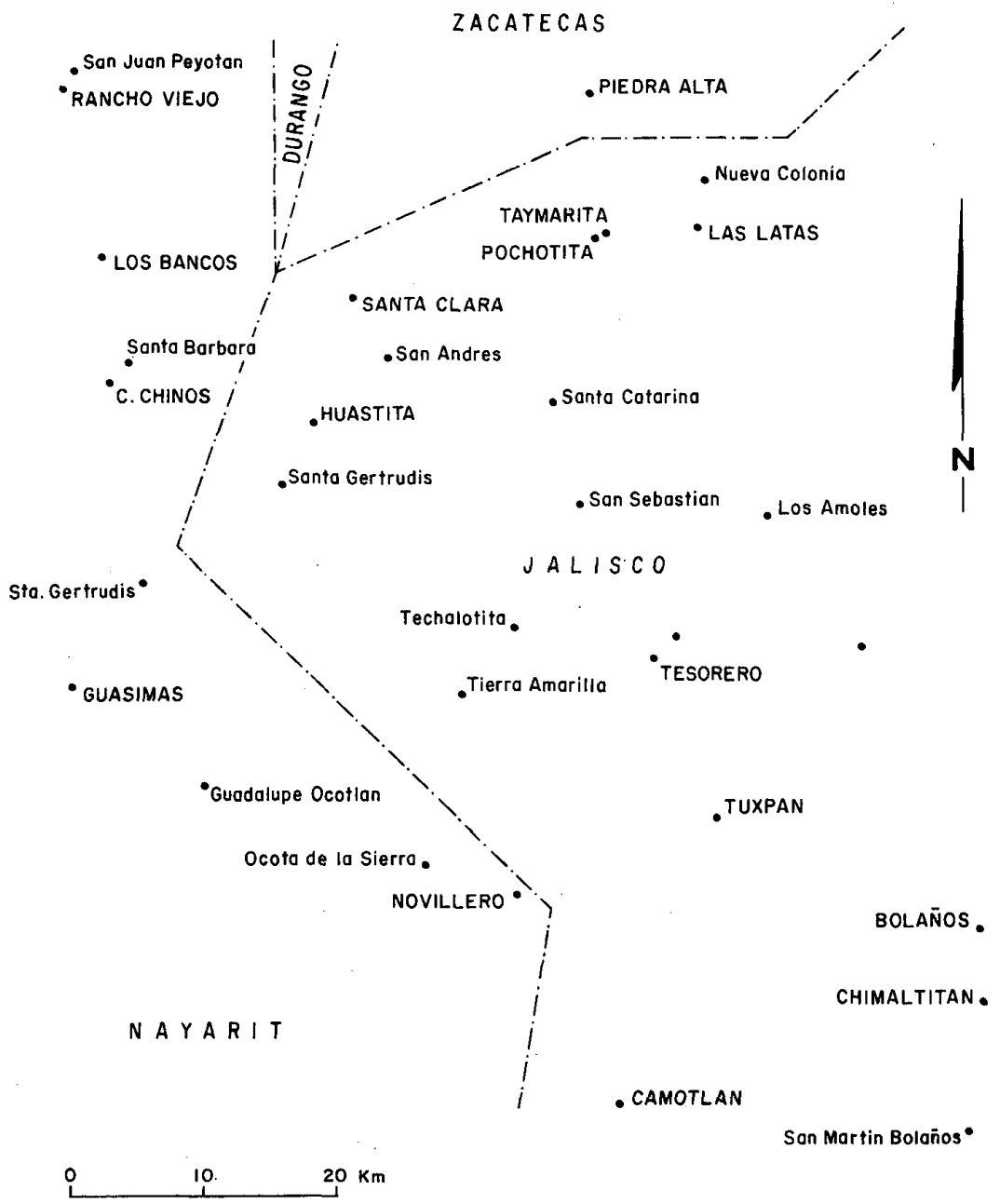


les, los huainamotas, los coras, los coanos, los tecuales, los guazamotas. Sobre la historia remota de estos grupos se sabe poco; por su lengua pertenecen al grupo uto-azteca; por su cultura, según el estado en que los encontraron los españoles, eran seminómadas, recolectores y cazadores. ${ }^{1}$

Con la llegada de los españoles, aunque tardaron bastante en adentrarse en esta parte de la Sierra Madre Occidental, se cree hubo un reacomodo de la población indígena asentada en la planicie costera y en el altiplano noroccidental efectuándose una concentración y un natural repliegue hacia la sierra, para alejarse y protegerse de los invasores. Se habla del aislamiento casi total en que vivieron los habitantes de esta parte de la Sierra Madre durante las primeras décadas de dominio español, en relación con el mundo hispánico. Esto está por verse. En cuanto avanza la búsqueda y crece la información se cree cada vez menos en el total aislamiento de estos grupos indígenas. El que no hayan tenido asentamientos continuos de españoles en su territorio, no asegura el que no hayan tenido contacto. Contacto que pudo haberse efectuado de muy diversas maneras: entrada de fugitivos de la ley, de los insistentes misioneros, de los buscadores de minas, de comerciantes ávidos y de aventureros. Sin contar el contacto que los indigenas hubieron logrado establecer en sus escapadas de la sierra.

No obstante, hay que decirlo, la entrada y el dominio español fue mucho más tardía y superficial que

${ }^{1}$ Gerhard, North, 1982, pp. 39-42. en muchas otras regiones de México. Para el gobierno español esta zona no se consideró afianzada sino con la reducción de los coras en 1721.

\section{LOS MISIONEROS FRANCISCANOS}

Fueron los frailes franciscanos quienes más temprano entraron a estas sierras. Desde mediados del siglo XVI no faltó misionero aventurero que, con peligro de su vida, decidiera salvar almas. No fueron pocos los misioneros que en esta parte de la sierra fueron sacrificados por alguno de los varios grupos de naturales que la ocupaban. Pero parece que esto, en lugar de aminorar su celo, lo aumentaba y poco a poco los franciscanos fueron sentando conventos y misiones que cercaban y presionaban a los indios a someterse.

La mayoría de los viejos poblados que nacieron en la sierra tuvieron su origen en alguna fundación misional. Así nació Camotlán hacia 1616. Antes ya se habian fundado en la región otros conventos: en Huainamota hacia 1582, en Colotlán en 1591 y en Huaximic en $1610 .^{2}$

\section{PRIMERAS NOTICIAS}

Las noticias que tenemos de este poblado durante su primer siglo de vida son pocas, por no decir inexistentes. El padre Tello informa de su fundación y el padre Arias Saavedra lo enumera entre los pueblos de la sierra.

2 Tello, Crónica, 1984, libro II, t. Ill, pp. 244, $301,357$. 
Camotlán nació como una congre. gación de huicholes mezclados posiblemente con otro grupo indigena. Perteneció civilmente al gobierno de Colotlán, distrito que, por circunstancias especiales que no señalaremos aquí, gozó de una jurisdicción especial, que permitió a sus habitantes: no pagar tributo, poseer legalmente muchas más tierras que las legalmente permitidas a otros grupos indígenas, gozar de fuero militar por estar organizados en milicias al servicio del rey, depender judicialmente de su capitán protector y justicia mayor y no de otra autoridad.

Aunque las leyes les daban tantas prerrogativas, la realidad fue otra. Las tierras de los indígenas, aunque inhóspitas y de difícil acceso, no dejaron de ser codiciadas. Con frecuencia la ley los amparaba, pero les fue muy dificil sobreponerse a las presiones de los mineros y colonos de los contornos, que reclamaban con urgencia tierras para seguir beneficiando sus metales. Cuando la minería no fue la causa, las razones para meterse en estas tierras barrancosas no faltaron, siendo las demandas siempre lo suficientemente amañadas o tranquilamente falsas, para que las autoridades virreinales, con asombroso candor, tomasen las verdades de los denunciantes como moneda contante. Esta situación provocó una de las rebeliones más importantes en el distrito de Colotlán.

\section{LA REBELIÓN DE 1702}

Los habitantes del pueblo de Camotlán participaron en un rebelión, unidos a otros 10 o 12 pueblos del mismo distrito, que tenían reclamos muy precisos que realizar contra sus autoridades y contra los colonos españoles que poco a poco se iban introduciendo en sus tierras, desposeyéndolos.

Los motivos de la rebelión fueron claros. Los indígenas veían que sus tierras eran invadidas y que las autoridades no respondian siquiera. En uno de los múltiples alegatos que se presentaron a raíz de esta sublevación, la cabeza del movimiento alegó, con gran fuerza, que no se trataba de una rebelión sino tan sólo de un recurso extremo para que sus quejas fuesen escuchadas. Después de tres meses de inquietud y de haber ajusticiado a su capitán y justicia mayor, todo volvió a la calma: los misioneros pudieron regresar a sus pueblos. Por el informe de uno de ellos nos enteramos de la situación en que se encontraba la sierra y de que el pueblo de Camotlán solicitó que se le otorgara su título, por haber perdido el que ya tenía. Este mismo fraile, Juan de Ribera, cuenta cómo fue llamado por los indígenas del mismo Camotlán para que fuera a oficiar y cómo solicitaban que se permitiera al padre fray Joseph de la Navidad se quedase con ellos.

Por esta rebelión la corona se dio cuenta de la situación de la sierra. Al año siguiente (1703) envió un comisionado, el oidor don Juan de Somosa, para que escuchara las quejas de indios y españoles y sus pretensiones sobre tierras. Muchos pueblos de la región se refieren a la visita del oidor Somosa y al año de 1703 para señalar el momento en que sus tierras les fueron medidas, si no tituladas. 
Cuatro años después del levantamiento se seguían efectuando diligencias y averiguaciones; así sabemos que Asencio de la Cruz era ese año de 1707 el alcalde de San Juan de Camotlán.

\section{LOS RECLAMOS DE 1752}

Conforme el tiempo pasaba, el dominio español se iba consolidando en la región y se hacía patente a causa del descubrimiento de reales de minas y la llegada de nuevos colonos. Cuando en 1748 se descubrió una de las más ricas vetas de la Nueva España del siglo XVIII, en el real de Bolaños, las presiones sobre los pueblos indígenas se acentuaron, ya fuese para obligarlos a trabajar en las minas, a arrendar sus tierras o a permitir la explotación de sus bosques en beneficio de la minería.

En 1752 once pueblos de la sierra encabezados por Colotlán e incluidos San Juan de Camotlán, Apozolco y Santiago de Ostoco, enviaron un largo escrito al virrey para defenderse de las acusaciones de los oficiales reales, corregidor y mineros de Bolaños. Los indígenas señalaron que los cargos hechos en su contra tenían como fin ponerlos a mal con las autoridades virreinales para que se les castigara quitándoles sus tierras.

En este escrito de 20 páginas exponen ampliamente cómo ven ellos la situación, revirtiendo contra quienes los inculpan las acusaciones de que son objeto. Si los mineros se quejan porque no tienen pastos para alimentar sus muladas, los indígenas responden enumerando el número de animales que pastan en sus tierras y la pequeña cantidad que reciben por este servicio:
Nos da don Joseph de Arrivarrojo, por cada un año treinta pesos, y tendrá como setecientas mulas. Don Juan de Feria da cincuenta pesos tiene trescientas mulas. Don Francisco Antonio de la Brena, da quince pesos y tiene trescientas mulas. Don Francisco Xavier Ulivaren, quince pesos y son quinientas mulas. Don Joseph Paniagua diez pesos y tiene ciento cincuenta mulas. Don Joseph Moscoso, veinte pesos, cien mulas. Éstos son los principales mineros que mantienen haciendas gruesas en dicho Real y que a don Joseph de Arrivarrojo, pongamos por caso, le rendirán la molienda de las setecientas mulas, diez mil marcos de plata, que regulados éstos con el precio de treinta pesos que de su locación percebimos, en ningún racional y prudente juicio se calificará excesivo $[\ldots]$ y más cuando en dichos arrendamientos no se les pone témino señalado, ni se sujetan a lugar determinado si no es que experimentan por esta libertad no tener pastos suficientes para su habilitación $[\ldots]^{3}$

En esta ocasión también alegaron los derechos que en la Ley 9 título $3^{\circ}$ Libro $6^{\circ}$ de la Recopilación de Lejes de Indias se les concedía. En esta ley se les permitía conservar las tierras que hubieran tenido antes de reducirse, tanto las que poseyeran a título de comunidad como de particulares, teniendo las comunidades derecho a poseer hasta tres leguas por cada viento. A esta ley apelaron los pueblos ésta y muchas otras veces por ser el fundamento legal que más amplitud daba para la defensa de sus tierras.

Los conflictos por tierras nunca han

\footnotetext{
${ }^{3}$ Archivo General de la Nación (AGN), Indios,
} 
tenido fácil solución y, aunque en esta ley se daba a parentemente razón a los pueblos indígenas, la realidad fue otra. Para empezar, no todos los pueblos tenían sus títulos "en buena y debida forma" y esto se volvió un muy serio impedimento para que pudiesen defenderse cabalmente. Por otra parte, cierto es que las tierras que los indígenas de esta zona reclamaban eran muy extensas y, muy posiblemente, ni la tramitación de sus títulos bajo todas las de la ley les hubiese podido amparar todas las tierras que reclamaban.

No podemos saber cuántas tierras amparaba el título de Camotlán. Suponemos que éste existió por la petición que hizo en 1702 el padre misionero a las autoridades para que se le volviera a sacar. Lo que sí sabemos con certeza es que las presiones de los colonos que se asentaron en esta región fueron constantes y que, a fuerza de perseverancia, lograron posesionarse de tierras que los indígenas consideraban propias.

\section{MERCEDES Y COMPOSICIONES DADAS EN EL SIGLO XVIII}

Tenemos registradas varias denuncias y mercedes de tierras cercanas o colindantes con Camotlán, con Ostoco, con Huajimic, con Apozolco y con San Sebastián. La más temprana es de 1711. Juan de Aguilar mandó un escrito a la Audiencia diciendo que ya tenía 6 años de vivir en el distrito de Jora, en donde era dueño de bastante ganado, pero no tenía tierras propias, por lo que se había puesto a buscar algún realengo para denunciarlo. Que ya había encon- trado lo que quería, que lo había llamado San Judas Tadeo y que, en sus cercanías, no había más que un vecino, un indio de Huajimic llamado Gaspar, pero retirado como a una legua, por lo cual no pensaba que se le perjudicase si a él se le daban las tierras que pedía.

Pero como ya señalamos, las denuncias y mercedes de tierras fueron más frecuentes a raíz del descubrimiento de la veta del Real de Bolaños, hacia 1750. Uno de los primeros denuncios que se presentaron y que empezaron a afectar directamente a Camotlán fue el realizado en 1766 por don Joseph Antonio Pérez de Contreras, minero y vecino de Bolaños. En diciembre de ese año, una vez aceptado el denuncio por la Audiencia, el teniente de alcalcle mayor de Hostotipaquillo procedió a efectuar las diligencias y medidas que darían origen a la hacienda de Quelita. En esta ocasión se mercedaron siete sitios de ganado mayor al denunciante, por los que pagó 120 pesos a la Hacienda Real. En el título de propiedad que se entregó a Pérez de Contreras, el 25 de febrero de 1767, se especificaba que los naturales de Camotlán y de Ostoco no habían salido perjudicados con estas medidas. En estas diligencias llama la atención la rapidez con que todos los trámites se efectuaron, acostumbrados como estamos a la morosidad de la burocracia virreinal: para acelerar los trámites, se perdonaron los pregones para el remate de las tierras denunciadas y la ocupación obligatoria de diez años para poder obtener una mercedación.

Apenas pasados cuatro años, el mismo Pérez de Contreras realizó otro denuncio en las cercanías de Camo- 


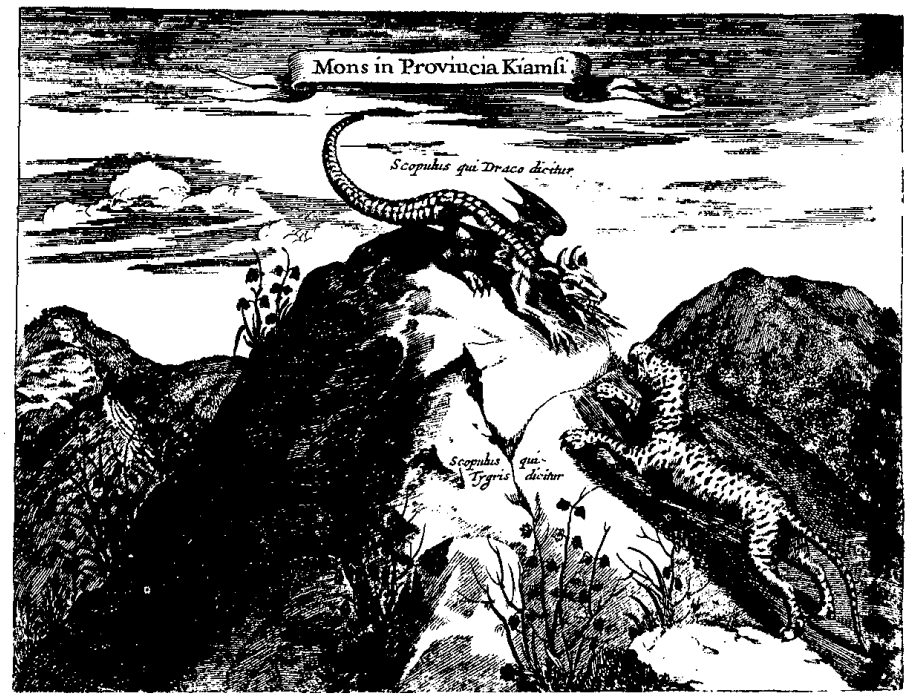

tlán. En esta ocasión, se le midieron tres sitios de ganado mayor en tal forma ya próximos a las tierras de los naturales de este pueblo que, durante las diligencias efectuadas en el mes de junio de 1770 , se midió el sitio que pretendidamente tenía el pueblo, y digo pretendidamente porque no pudieron presentar sus títulos ya que desde hacía muchos años sabían se les habían quemado. Con este denuncio de Pérez de Contreras, las medidas también llegaron hasta los linderos del pueblo de Ostoco.

Al finalizar las diligencias, los naturales de Camotlán y de Ostoco se presentaron ante el juez de estas medidas para demostrar su inconformidad, diciendo que se les molestaba y perjudicaba. El juez registró su queja y les señaló su derecho de llevarla ante la
Audiencia en un periodo de tres meses. Lo que no deben de haber efectuado ya que el 25 de octubre de ese mismo año de 1770 el presidente de la Audiencia reconoció como buenas las diligencias del denuncio de Pérez de Contreras y le otorgó un nuevo título por los tres sitios de ganado mayor, más cuatro caballerías de tierra, que se sumaban a las siete obtenidas en 1766. Con estas mercedes se inició la consolidación de la hacienda de Quelita, que años más tarde se apropiaría de las tierras y del nombre del pueblo de Camotlán.

Los denuncios y mercedes anteriores no fueron los únicos; tenemos registrados otros, como el efectuado en 1767 por un tal don Juan de la Calle que mandó un escrito a la Audiencia en donde decía que entre Jora y Ca- 
motlán había tierras realengas, y que como las necesitaba para su uso, las denunciaba.

En 1770 doña Rita Antonia Flores del Castillo, quien se dijo vecina de Camotlán, denunció una tierra "realenga" en el puesto de las Huertas, que lindaba por el norte con el mismo pueblo de Camotlán, al sur con el Pinal, al oeste con la sierra de Totoliques y al poniente con la cumbre de la sierra de Santa Clara, todos estos puntos colindantes por el oeste con Camotlán. Se le midieron dos y medio sitios y se le hicieron merced, también con la dispensa de la posesión obligatoria de diez años. ${ }^{4}$

En 1776 Tomás Antonio Pinedo, vecino de Jora, mandó un escrito a la Audiencia denunciando dos sitios de tierras en el Capulín, "desde la cumbre que sale de Huaximic rumbo a Jora". En 1780, diez años después de su primer denuncio, la señora Antonia Flores del Castillo, ya viuda de Anselmo Salazar, efectuó otro, ahora del sitio llamado Rincón Grande, obteniendo esta vez que se le mercedaran tres cuartas partes de sitio de ganado mayor y dos y media caballerías, extensión sin duda insignificante, pero que iba agrandando la propiedad de la señora Flores del Castillo y sobre todo iba cercando al pueblo de Camotlán.

Así, poco a poco, sitio por sitio, se fueron mercedando estas tierras que se consideraban realengas, pero por su cercanía a los poblados resulta un tanto dudoso que lo fueran realmente.

4 Archivo de Instrumentos Públicos, Tierras y Aguas, Guadalajara (AIPT y^), 182, leg.42, exp. 21 .
Las anteriores no fueron las únicas mercedadas, hubo otras en donde las tierras pretendidas ya no fueron de uno o dos sitios, sino extensiones mayores. Estos denunciantes fueron gente del mineral de Bolaños, ricos mineros que contaban con medios para efectuar todas las diligencias necesarias, tan costosas en tierras tan escabrosas y accidentadas. Los principales denunciantes fueron don Antonio Pérez de Contreras de quien ya hablamos y don Miguel Maximiliano de Santiago.

\section{MERCED QUE DIO ORIGEN A IA} HACIENDA DEL TULE (1767)

Don Miguel Maximiliano de Santiago era un minero de Bolaños, dueño de haciendas de beneficio, quien en noviembre de 1766 presentó ante el juez privativo de ventas y composiciones una solicitud para que se le dieran en merced algunas tierras en las inmediaciones de este real. Señalaba en su demanda que él ya había efectuado algunas averiguaciones sobre las tierras realengas que se encontraban en los contornos de los pueblos de Tenzompa, Huilacatitan y Chimaltitan, todas cercanas a Bolaños y por tanto muy a propósito para sus necesidades.

Para fines de marzo del año siguiente -1767- se iniciaron las diligencias y medidas de las tierras denunciadas, que eran conocidas con los nombres de Sonacata, Charco Azul y el Tule. Por lo accidentado de las tierras denunciadas, los comisionados tardaron un mes en realizar las medidas, resultando tres sitios de ganado mayor, 
más otro medio más. Una vez terminadas las medidas se citó a los colin. dantes para que presentaran su queja, si es que resultaban perjudicados. Se mandó citatorio a los pueblos de Ten. zompa, Huilacatitan, San Sebastiản y el de Asqueltan. Aparentemente ningún pueblo presentó contradicción. De los que se presentaron a declarar ninguno se dijo afectado.

Estas medidas, por el momento, no llegaron hasta el pueblo de Camotlán, aunque hay que decir que este denuncio se acercaba ya mucho a sus tierras porque en una de estas medidas, al fijarse un lindero, se señaló que la mojonera cruz poniente del sitio de Charco Azul estaba en un cerro fragoso y montuoso, que daba vista al valle del pueblo de los indios de Camotlán.

Estas diligencias no concluyeron sino hasta 1780 , en que se retomó el expediente. El 30 de enero de 1781 se dio a don Miguel Maximiliano de Santiago un título expedido por la Audiencia de Guadalajara, mercedándole por composición los tres sitios y medio ya señalados.

Merced a An'tonio PEREz de CONTRERAS 1777-1784. FORMACIÓN DE, LA HACIENDA DE CAMOTLÁN

Ya hemos presentado las mercedes obtenidas por Pérez de Contreras en $1766 y$ en 1770 , pero no fueron las únicas, pues en 1777 efectuó otro denuncio. El expediente de este denuncio no lo tenemos completo, en el Archivo Histórico de Jalisco se encuentra un resumen de estas diligencias, pero con esta información se puede entender y reconstruir lo sucedido.

En esta ocasión los sitios denunciados fueron 18 y se encontraban en el partido de San Juan Bautista de Camotlán, jurisdicción de Colotlán. Las medidas las realizó el alcalde mayor de Hostotipaquillo. Al medirse los sitios denunciados se encontró que colindaban: por el sur con tierras del propio denunciante, o sea, con el sitio de Portezuelos; por el poniente con las de don Tomás Pinedo; por el oriente con la sierra de San Sebastián que era el lindero de los pueblos de Camotlán y Ostoco. También en este caso las diligencias no llegaron a su fin sino varios años después, en 1784, cuando se retomaron los expedientes y se dio título a Pérez de Contreras de los 18 sitios denunciados. Los sitios que se mercedaron a Pérez de Contreras comprendían los puestos de Tuspa, Pescaditos y Jazmines, que reclamaba el pueblo de San Sebastián como suyos.

Pero los denuncios realizados en esta zona no terminaron aquí. Ya vimos que no fue sino hasta 1781 en que se titularon al señor Miguel Maximiliano de Santiago los tres sitios y medio que denunció desde 1766. Apenas lograda esta titulación, el propio Miguel de Santiago efectuó otro denuncio, ahora de mayor consideración, ya que pidió la composición de nueve sitios de ganado mayor, más 16 caballerías de tierra que colindaban con los que ya se le habían mercedado, que habían dado nacimiento a la hacienda llamada el Tule, que tendremos ocasión de encontrar posteriormente.

Las medidas de este nuevo denuncio se iniciaron en abril de 1781 , y fue- 
ron realizadas por el teniente de alcalde mayor de Tlaltenango don Tadeo Canencio. Las tierras que se denunciaban colindaban con Huejuquilla, Tenzompa, Santa Catarina, San Sebastián, Huaximic y con las tierras recién mercedadas a Pérez de Contreras.

El denunciante no pidió que se midiera sino hacia las colindancias con San Sebastián y con la hacienda de Pérez de Contreras, alegando que sus cabalgaduras estaban muy débiles y que no tenía caso por ahora mandar citar a los otros pueblos. La realidad es que había corrido la voz de que los de San Sebastián no tenían sus titulos y que era la ocasión para hacerse mercedar las tierras que este pueblo consideraba suyas ya que, por el momento, no podía comprobar sus derechos.

\section{NUEVAS MEDIDAS PARA IA HACIENDA DEL. TULE}

Se citó a los colindantes; Pérez de Contreras mandó a su mayordomo diciendo que no presentaba sus títulos porque, como tenía un pleito con San Sebastián, no se los había entregado la Audiencia. Los de San Sebastián dijeron que para qué iban si no tenían sus títulos. Las medidas se empezaron en el puesto de Sonacata y de allí se prosiguieron por los cuatro vientos, incluyendo en las medidas los ranchos de Ratontita, Ocota, parte del puesto de Tuxpa, porque la otra ya la tenía mercedada Pérez de Contreras. Todos estos lugares eran considerados por los de San Sebastian como suyos.

En las diligencias se citaron pun- tos que aún ahora nos pueden servir de referencia para reconocer las tierras que se estaban midiendo: "se dirigió el abujón hacia la cumbre de un cerro que está al oriente de la barranca que llaman de San Bernardo, atravesándose con esta línea, el río de San Sebastián que corre de norte a sur". O se midió "por tierras barrancosas, arroyos y despeñaderos; al cabo de tres días nos emparejamos con el citado punto, sin ser posible conducirnos a él, por impedirlo la barranca del río de Camotlán [...]" Pero aquí detenian sus medidas por empezar las tierras de Pérez de Contreras que llegaban hasta parte de [...] "unas mesas que se llaman de Tuspa y río de $\mathrm{Ca}$ motlán" señalando que al pie de este cerro de Tuspa pasaba el camino de arrieros que sube para Camotlán. A este cerro lo señalaron en el plano levantado con la letra "Y".

Al terminarse las medidas se señaló que en el acordonamiento se com. prendian los puestos

nombrados San Cayetano, parte del río de San Sebastián; los ranchos nombrados Ocota, Ratontita y Tuxpa, Coamostita y Guisaspa, pertenecientes a los indios de San Sebastián aunque sin otro título que el de hallarse estos naturales extendidos por varias barrancas y arroyos distantes de su pucblo cinco y seis leguas [...]

Los de San Sebastián presentaron varios escritos, pero como no pudie. ron presentar sus títulos, el 21 de febrero de 1782 se dio a Miguel Maximiliano de Santiago el título de las tierras denunciadas. 
Totalizando las tierras mercedadas que tenemos registradas a Antonio Pérez de Contreras y a Miguel Maximiliano de Santiago, en sus haciendas de Camotlán y el Tule, para 1784 estos dos señores eran dueños de 40 sitios de ganado mayor y veinte y tantas caballerías. Extensión que en sí podemos considerar como moderada para los usos de la época y la calidad de las tierras mercedadas, siempre y cuando no se hubiesen afectado las tierras de varios pueblos indígenas de la región. A éstas habrá que agregar las otras mercedes, que en menores extensiones se habían repartido a diferentes denunciantes.

Tres pueblos fueron los principales afectados: Camotlán, Ostoco y San Sebastián. En qué medida lo fueron, no lo podemos saber, por no haber podido localizar sus títulos y medidas. Presumimos que, por el momento, el más afectado fue el de Ostoco, el cual, pocos años después de las últimas medidas para Pérez de Contreras, fue declarado desierto. Camotlán, por el momento, conservó por lo menos las tierras de su fundo, únicas que los denunciantes estuvieron dispuestos a respetarle. Lo de San Sebastián es más confuso ya que, efectivamente, muchas de las tierras que reclamaba le fueron afectadas, pero reclamaba tantas que esto facilitó el despojo.

\section{EL PERIODO DE LOS INFORMES}

Las tres últimas décadas del siglo XVIII fueron ricas en informes administrativos. La burocracia ilustrada necesitaba tener información para poder gober- nar. El distrito de Colotlán, por las características de su administración, recibió especial atención y los informes que se produjeron sobre diferentes aspectos de su administración nos permiten conocer la situación en que se encontraba Camotlán y sus contornos a finales de este siglo. En uno de estos informes, mandado recabar por el virrey en 1783, el gobernador de Colotlán señaló:

En la citada sierra se hallan Camotlán y Ostoco que componen esta doctrina, gozando estos lugares competentes tierras de labor en planes frondosos, aguas y sombríos, para criar toda especie de ganados y sus gentes versadas en el idioma castellano, despiertos en trato y contrato, distantes de Colotlán de sesenta a sesenta y cinco leguas.

En este informe el gobernador de Colotlán propuso que estos dos pue. blos pasaran a Hostotipaquillo, para que tuviesen acceso más rápido a sus jueces ya que, como señaló, la cabecera y lugar de residencia de su juez les quedaba bastante lejos. ${ }^{5}$ En esta misma información de 1783-84, el alcalde de Jerez señaló a Camotlán como doctrina, con Ostoco y Aposolco.

\section{Vistra de Fél.ix M. Calleja, 1790}

Las siguientes notas proceden de la información que levantó el joven capitán Calleja, caminante infatigable y eficaz visitador, y considerablemente nuestro conocimiento sobre la situación de la sierra a finales del siglo XVIII.

5 Velázquez, Colotlán, 1961, pp. 41-42. 
No tomamos su narración por no alargar este texto, pero vale la pena retomar algunas de las anotaciones hechas por él.

Calleja recorrió entre muchos otros pueblos de Colotlán, los de Camotlán, Ostoco, San Sebastián, San Andrés Coadmiata, como él lo llama, y Santa Catarina, que tienen en común en esta época ser todos pueblos huicholes. En cada uno de ellos fue levantando un censo de los hombres que prestaban servicio miliciano, de la extensión de sus tierras y de sus usos y costumbres. Los señaló como los mejores flecheros de la sierra, de muy buena puntería. Estos cinco pueblos a decir de nuestro informante vestían igual, hablaban la misma lengua y habitaban lo más áspero de la Sierra Madre. Sembraban muy poco y vivían en gran medida de la caza y de la pesca y tenían un corto tráfico de sal. Dijo que eran menos tímidos que otros que había visitado y que veneraban muy poco a los misioneros.

En el censo que levantó asignó para Camotlán 80 familias, con un total de 609 habitantes. A su paso, Calleja encontró el pueblo de Ostoco desierto, achacando esto a la multitud de alacranes que había en ese lugar, por lo cual sus habitantes -a su decir-se habían juntado con los de Camotlán. No hay que olvidar que, pocos años antes al paso de Calleja, fueron justo las tierras de Ostoc las que fueron mercedadas a Pérez de Contreras y a

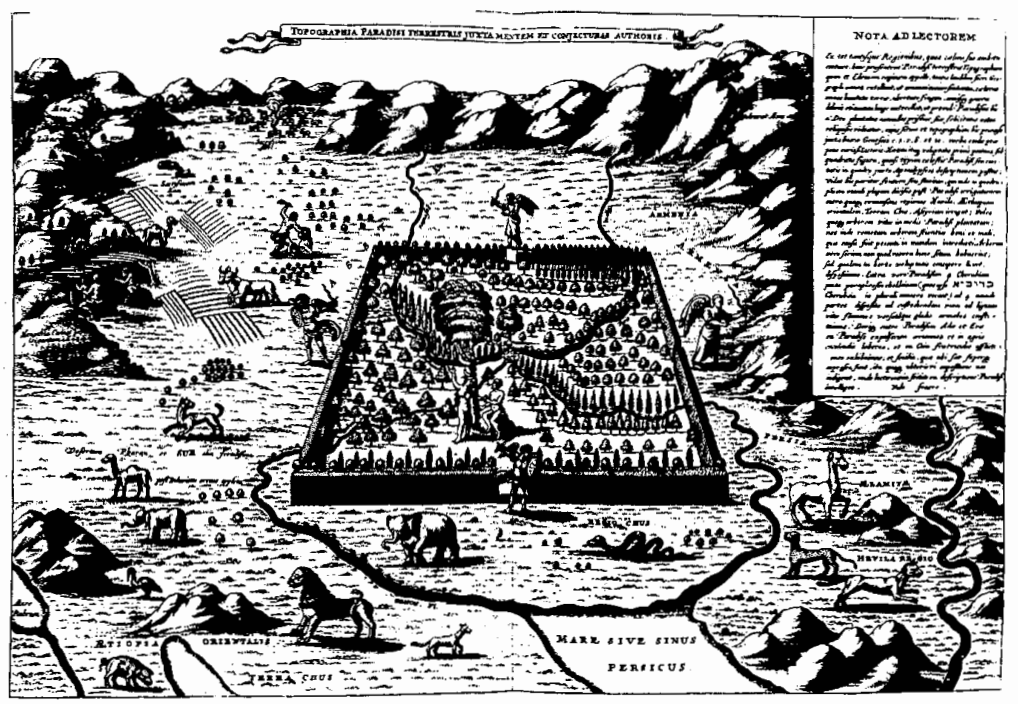


Miguel Maximiliano de Santiago. ¿No sería más bien ésta la razón para encontrarlo desierto?

\section{REORGANIZACIÓN ADMINISTRATTVA Y ECLESIÁSTICA}

Entre las muchas recomedaciones y propuestas que Calleja realizó como resultado de su visita para la reorganización del distrito de Colotlán resaltan, en primer lugar, la de que se le diera otra organización administrativa, en donde sus jueces pudiesen más fácilmente estar al pendiente de lo que sucedia, para lo cual se dividiría este distrito en cuatro tenientazgos. El primero, el que nos interesa por comprender al pueblo de Camotlán, tendria su cabecera en el Real de Bolaños y de él dependerían los siguientes pueblos: Acaspulco, Tepisuaque, Mamata, Apozolco, Azcaltan, San Sebastián, Santa Catarina, San Andrés Coadmiata, Camotlán, Ostoco, Huilacatitan, Pochotitán, Chimaltitan y Coacuasco. El segundo tendría como cabecera Colotlán, el tercero Huejuquilla y el cuarto Nueva Tlaxcala. Cada uno de éstos con sus pueblos agregados.

Otra de las recomendaciones de Ca. lleja consistió en que se asentaran por to menos diez familias de españoles en los pueblos de este distrito, para asi fomentar el mestizaje y la asimilación de estos indígenas a la vida colonial. También consideró necesario que se les cobrara tributo a los pueblos, in-

6 "Diario formado por el capián de infantería don Felix Calleja", Archivo General de Indias (AGI), Guadalajara, 393. discutible signo de vasallaje al rey. Por último que, poco a poco, se les impulsara a llevar una vida sedentaria, sobre todo a los pueblos huicholes, que aunque tenían sus pueblos fundados, los ocupaban por cortos periodos. Para lograr esto se necesitaba que cultivasen sus tierras y que se olvidasen de la caza, una de sus principales fuentes de vida. Con esto también se les quitaría lo belicoso, porque al perder la costumbre de cazar, también olvidarían el manejo del arco y las flechas.

Ninguna de las propuestas de $\mathrm{Ca}$ lleja pudo ponerse en práctica por la rígida oposición que mostraron los pueblos de este distrito a aceptar que se les quitasen sus privilegios. Tan sólo dos poblados, de los treinta y dos que existian en este distrito, aceptaron la instalación de españoles. En algunos, como en Huejuquilla, la oposición fue violenta y las autoridades tuvieron que dar marcha atrás en sus pretensiones.

\section{OTRAS NOTICUAS SOBRE CAMOTLÁN}

En 1799 el obispo de Guadalajara decidió relevar a los padres franciscanos que estaban a cargo de los curatos de Camotlán, Amattán de Jora, Aposolco y Huajimic y ponerlos bajo administración secular. El obispo comisionó al cura de Bolaños, don Martín de Góngora, para efectuar los estu. dios necesarios para la nueva division eclesiástica. En el expediente que se compuso durante estas diligencias se resaltan algunos datos de importancia. Por ejemplo, que el curato de Camotlán obedeciese los mandatos del gobernador interino del gobierno de 
Censo del curato de Camotlán: 1799

\begin{tabular}{ccccccccc}
\multicolumn{3}{c}{ Españoles } & \multicolumn{4}{c}{ Indios de pueblo } & \multicolumn{3}{c}{ Castas } \\
1 & 2 & 3 & 1 & 2 & 3 & 1 & 2 & 3
\end{tabular}

$\begin{array}{llll}\begin{array}{l}\text { Camotlán } \\ \text { Quelita } \\ \text { Totolequeste }\end{array} & & & \\ \text { Los Jaras } & 2 & 5 & 3 \\ \text { El Portezuelo } & 1 & 4 & 3 \\ \text { La Ciénega } & 2 & 4 & 2 \\ \text { El Tirador } & & & \\ \text { Ostoco } & & & \\ \text { El Rosario } \\ \text { San Antonio } \\ \text { Tlaxcala }\end{array}$

$\begin{array}{lll}23 & 66 & 18\end{array}$

$1=$ número de familias; $2=$ adultos; $3=$ niños.

Población en los pueblos (cabecera)

\begin{tabular}{|c|c|c|c|c|c|c|c|c|}
\hline \multirow[b]{2}{*}{1} & \multicolumn{2}{|c|}{ Españoles } & \multicolumn{3}{|c|}{ Indios de pueblo } & \multicolumn{3}{|c|}{ Castas } \\
\hline & 2 & 3 & 1 & 2 & 3 & 1 & 2 & 3 \\
\hline & & & 23 & 66 & 18 & & & \\
\hline & $\begin{array}{r}7 \\
23\end{array}$ & $\begin{array}{l}3 \\
8\end{array}$ & $\begin{array}{r}8 \\
22\end{array}$ & $\begin{array}{l}20 \\
64\end{array}$ & $\begin{array}{r}9 \\
20\end{array}$ & $\begin{array}{l}11 \\
39\end{array}$ & $\begin{array}{l}29 \\
84\end{array}$ & $\begin{array}{r}7 \\
36\end{array}$ \\
\hline & 20 & 10 & 57 & 146 & 96 & 20 & 49 & 0 \\
\hline
\end{tabular}

$1=$ número de familias; $2=$ adultos; $3=$ niños.

Camotlán

Amatlán

Huajimic

Apozolco

Población total en los curatos

\begin{tabular}{|c|c|c|c|c|c|c|c|c|c|}
\hline & \multicolumn{3}{|c|}{ Españoles } & \multicolumn{3}{|c|}{ Indios de pueblo } & \multicolumn{3}{|c|}{ Castas } \\
\hline & 1 & 2 & 3 & 1 & 2 & 3 & 1 & 2 & 3 \\
\hline Camotlán & 5 & 13 & 8 & 23 & 66 & 18 & 36 & 122 & 67 \\
\hline Amatlán & 14 & 47 & 27 & 8 & 20 & 9 & 117 & 364 & 182 \\
\hline Huajimic & 9 & 41 & 10 & 22 & 64 & 20 & 49 & 121 & 55 \\
\hline Apozolco & 7 & 24 & 14 & 66 & 172 & 105 & 33 & 84 & 36 \\
\hline
\end{tabular}

$1=$ número de familias; $2=$ adultos; 3 =niños. 
Colotlán, don Pedro Antonio Trelles, lo que significa que Camotlán seguía unido a este gobierno.

En su estudio el comisionado delimitó el territorio correspondiente a cada curato. El de Camotlán abarcaba once pueblos con un total de $66 \mathrm{fa}$ milias y 266 personas. El curato iba de los 25 grados del primer cuadrante a los 35 del segundo, o sea de Tlaxcala a Totolequeste con 10 leguas y media de largo. De ancho iba de Quelita a la Ciénega, o sea, de los 50 grados del segundo cuadrante a 30 grados del cuarto con tres leguas. Este curato colindaba con los curatos de Chimaltitan, Aposolco, Huajimic, Amatlán de Jora y la mision de San Sebastián.

Considerando el estudio realizado por el cura de Bolaños y el veredicto dado por el promotor fiscal, el obispo Ruiz de Cabañas decidió los siguientes cambios en la administración eclesiástica de estos curatos. Apozolco pasó a formar parte del curato de la Yesca, y Huajimic y Camotlán se unieron al curato de Amatlán de Jora que funcionaría como cabecera. ${ }^{7}$

No es vano aclarar que si estas trarısformaciones en la administración eclesiástica nos interesan, se debe a que en muchas ocasiones, en la organización de la administración civil, se tomaron como base las divisiones eclesiásticas. Pero, por lo visto, no se procedió a la reorganización administrativa de Colotlán, una prueba de ello es que en 1802 se tomó parecer al señor Evia, gobernador de Colotlán, sobre la conveniencia de reestructurar

7 Archivo Historico de la Mitra del Arzobispado de Guadalajara (AнM), Curatos, Camotlán. la administración de este distrito; éste contestó que en su opinión debían respetarse las antiguas divisiones distritales de estos pueblos porque, posiblemente, un cambio de tal naturaleza causaría malestar y rebelión en los naturales del distrito.

De la lectura de este censo podemos considerar de relevancia lo siguiente: Camotlán es el único poblado del curato que se sigue manteniendo indígena en su totalidad. En todos los demás pueblos y rancherías los españoles y castas, si no predo. minan, tienen ya una fuerte presencia. Ostoco, que fue señalado por Calleja como desierto, se reporta nuevamente poblado, pero ya no por indígenas, sino por castas. Sin duda esto significa que la lucha de los indigenas de este curato por conservarse aislados del mundo colonial, y por preservar sus tierras, está a punto de perderse al finalizar el siglo xvirI.

\section{LA REVOLUCIÓN DE INDEPENDENCIA}

Las noticias que tenemos sobre la gue. rra de Independencia en la región de Colotlán, y en esta parte de la Sierra Madre, son pocas. Sabemos que el grueso de la población de este distrito se unió al levantamiento. El 31 de marzo de 1811, el cura realista José Francisco Álvarez reportó que los de Colotlán y demás pueblos del distrito se habían rebelado. El 27 de este mismo mes el mismo cura consideró más prudente retirarse hacia Jerez en vista de que los enemigos eran muy numerosos. Los informes de Álva. rez, el comandante militar de las tro- 
pas realistas de Juchipila, Tlaltenango y Colotlán, hicieron que José Celestino Negrete llegara para reforzarlo y el 7 de abril de 1811 se enfrentó a las tropas rebeldes ocasionándoles bajas de 1500 hombres, pues 8000 o 10000 formaban el grupo de rebeldes de $\mathrm{Co}$ lotlán.

Periódicamente, durante 1811 y 1812 , se siguieron reportando hechos de armas en este distrito y en los colindantes: Hostotipaquillo, la Yesca, Ahuacatlán. Por los informes militares realistas se sabe que si se efectuaba un enfrentamiento, los enemigos insurgentes dejaban centenares de muertos $y$ heridos.

El pueblo de Apozolco se distinguió entre los rebeldes. Era capitaneado por Adanto Rodríguez, quien cayó preso en enero de 1812 . El subdelegado de Hostotipaquillo dijo en julio de 1812 a los habitantes de este pue. blo:

Los indios de Apozolco que después de indultados y mandados retimar a disposición del señor gobernador de $\mathrm{Co}$ lotlán para que aquel jefe los distribuya en parajes muy lejos de su fundo, no quieren escarmentar, pues muy distantes de cumplir con tal prevención se han abrigado en el pueblo de Mamata distante cinco leguas del mismo de Apozolco; de modo que validos de esta inmediación, con repetición se han introducido en este pueblo, y ocasionado perjuicios de consideración, siendo su proceder tan perverso que se han profugado muchos de ellos con el obstinado intento de incorporarse a las gavillas que ruedan por la sierra, las que en la semana pasada asesinaron a dos rancheros en el puesto del Órgano, y para consultar a la quietud y disminuir a estos malvados que la perturban seduciendo a otros, pido a V.S. se sirva expedir la conveniente recta orden para que el expresado señor gobernador recoja y separe a todos los indios que se encuentran por allí albergados con lo que vendrán a servir de algún sosiego los resguardos de Analco, la Yesca y Jora. ${ }^{8}$

La petición del subdelegado fue oída. El 10 de julio de 1812 el gencral Cruz, comandante de las fucrzas realistas de la Nucva Galicia, escribió al gobenador de Colotlán para que se ocupara del reacomodo de los indios de $\Lambda$ pozolco; se trataba de separarlos de su antiguo domicilio y reubicarlos en un lugar en clonde pudiera estar al pendiente de ellos, cuidarlos y castigarlos si lo merecían.

En junio de 1813 el comandante de armas del Real de Bolaños se internó por lo más áspero de la sierra para perseguir al indio Cañas, cabecilla de la sierra, que fue seguido durante algún tiempo por los pueblos huicholes. Paradójicamente fue un grupo de huicholes quien participó en la aprehensión de este rebelde en las confluencias de los ríos Huaina. mota y Mahuiloya.

En la sierra los estragos de la guerra pronto se dejaron sentir. Así, en noviembre de 1814 el padre Norberto Pérez ya anotaba las consecuencias de las epidemias y la hambruna sobre la población serrana. El padre cuenta a su obispo cómo estaban sufriendo los huicholes las consecuencias de la guerra y señaló cómo Huajimic y Ca-

${ }^{8}$ López, Insurgencia, 1984, t. II, p. 110. 
motlán habían sido abandonados y destruidos.

\section{La HaCIENDA DE CAMOTLÁN APARECE NUEVAMENTE}

Posiblemente fue este abandono to que facilitó que la hacienda de Camotlán se consolidara, usurpando definitivamente las tierras que tenía en litigio con los indios huicholes de San Sebastián. En 1815, en pleno periodo de guerra, don José Celectonio Martinez de Murguía adquirió de la señora Matiana Pérez la ya llamada hacienda de Camotlán. Por esta compra debe haber pagado un bajo precio ya que, ocho años después, una vez instaurada la paz, la vendedora inició un juicio de recesión de venta de la hacienda, por considerarse engañada al haber recibido en pago una cantidad que no correspondía a su valor real, ya que la vendió con desconocimiento de causa. 9

Poco tiempo después de haber adquirido la hacienda, posiblemente apenas pasados unos días, don Celedonio que, gracias a su participación en los cuerpos patrióticos realistas, ostentaba el grado de capitán, cargó una hipoteca sobre su recién adquirida finca. Se trataba de una cantidad considerable, 3063 pesos, que el marqués de Vivanco había dejado en un censo para que sus réditos se aplicaran a la creación y funcionamiento de una escuela de primeras letras en el Real de Bolaños, censo que debía ser mane-

${ }^{9}$ Archivo de la Biblioteca Pública del Estado de Jalisco (ABPEJ), legajo 63, Civil 1160, exp. 23, 1823. jado por el ayuntamiento. Este hecho, práctica tan común durante el periodo colonial, traería con los años múltiples complicaciones al ayuntamiento.

De don José Celedonio conocemos algunos datos que vale la pena anotar: en 1815, cuando adquiriố la hacienda, se declaró vecino de la hacienda de San Antonio de Padua, cercana a lluejuquilla, en donde tenía una tienda. En 1821 fue electo representante por el partido de Zacatecas a la diputación provincial, cargo que posiblemente ya no llegó a ocupar por haberse declaraclo entre tanto la Independencia. En 1823 se le instauró el juicio pedido por la señora Pérez de Contrcras, pero no sabemos qué resultado tuvo este pleito. Martínez de Murguía ofreció mañosamente regresar a la reclamante la hacienda, con la condición de que le diera la cantidad que él había entregado más el montante de las mejoras que había realizado durante su dominio. En este litigio el apoderado de la señora Pérez (esposa o hija de Pérez de Contreras) señaló los malos manejos de don José Celedonio, porque en el juzgado de Guadalajara tenia otros juicios pendientes. Ignoramos qué fue lo que pasó con don José Celedonio, ni cuándo la hacienda de Camotlán, que cargaba el censo a favor del ayuntamiento de Bolaños por la donación hecha por Vivanco, pasó a formar parte de los bienes del ayunta. miento.

\section{1: MÉXICO INDEPENDIENTE}

El distrito de Colotlán se conservó organizado militar y políticamente de 
la misma manera, aun cuando se implantó el sistema de intendencias. Esta organización se hạbía mantenido contra los deseos de la administración virreinal, que en no pocas ocasiones intentó remodelarlo, al igual que a su vecino Nayarit. Nunca lo logró a causa de su temor a que los naturales inconformes se rebelaran. A lo más que se llegó fue a juntar bajo un mismo gobernador a Colotlán, Nayarit y el corregimiento de Bolaños.

Otro intento de cambio fue el decretado por la diputación provincial en 1814 , con el cual se pasó el distrito de Colotlán a la provincia de Zacatecas y el de Nayarit a la de Tepic. En un documento redactado por esta diputación provincial, en que se enumeran las nuevas divisiones, se lee lo siguiente:

Colotlán. Este pueblo que ha sido cabecera de gobierno, lo será de su partido propio, confinando con los de Thaltenango, Juchipila, Jerez, Fresnillo, y por la sierra del Nayarit, hasta los términos de la provincia, debiendo comprender en su distrito las congregaciones de Monte Escobedo, pueblos de Mesquitic, Huejuquilla el Alto, San Nicolás, la Soledad, Tenzompa, Santa María de los Ángeles, Huejucar, Talcosagua, y demás pueblos de la sierra y que se titulaban antes de la frontera, que fuera de los expresados quedaran más cercanos a dicha cabecera que a las demás sus confinantes, observándose la misma regla, con las haciendas, estancias y rancherías que se hallaran en igual caso. ${ }^{10}$

${ }^{10}$ Muriá, Divisiones, 1976, p. 156.
Esta división muy posiblemente no llegó a ponerse en práctica, por el corto tiempo que la Constitución de Cádiz estuvo vigente en la Nueva España. De todas formas, en sus propuestas para modificar la división administrativa de los viejos distritos de Colotlán y Nayarit se dejaba abierta la posibilidad de colocar varios poblados en uno u otro de los nuevos distritos. Por ejemplo, se creó el distrito de Tlaltenango a donde debía pertenecer Bolaños. La Yesca, que había pertenecido a Hostotipaquillo, quedó en Ahuacatlán, por haber desaparecido su antigua cabecera.

Con el regreso de Fernando VII al trono y el desconocimiento a todos los cambios implantados por las cortes y la Constitución de Cádiz, la Nueva España regresó a su antigua organización, o más bien ni tuvo que regresar porque lo más probable es que no se hubiese logrado implantar esta reforma. Colotlán, Nayarit y Bolaños quedaron nuevamente unidos bajo un mismo gobierno.

Cuando en 1820 se volvió a implantar la Constitución de Cádiz, y se volvieron a organizar las diputaciones provinciales, no se retomó la división propuesta por la diputación de 18131814 sino que se continuó con la vigente en 1808, por lo cual, al declararse la Independencia Colotlán, Nayarit y Bolaños seguían formando un distrito.

Durante los tres primeros años de vida independiente, en general se con. tinuó con las mismas divisiones territoriales. Aunque la diputación provincial de Guadalajara desde 1822 retomó los trabajos ya iniciados por su 
homóloga de 1814, en cuanto a los estudios para establecer una división más adecuada. Estos trabajos se realizaban mientras a nivel nacional fracasaba el primer imperio, y se dejaba la puerta abierta a un sistema de gobierno diferente. La diputación provincial de Guadalajara, acorde con la tónica general, aprobó el 16 de junio de 1823 el "Plan general provisional del nuevo estado de Jalisco". Este plan estableció una división interna del estado que obedeció a la ya existente.

El que Camotlán siguiese perteneciendo al distrito de Colotlán es testimoniado en un oficio del 27 de marzo de 1822 , enviado al padre presidente de las misiones del Nayarit por el teniente don Ramón Vargas, en donde se lee lo siguiente:

Tenga muy presente atender del mismo modo en este punto a los pueblos de Ostoco y Camotlán del gobierno de Colotlán, por necesitar mucho de los auxilios de V. P. para que viéndose tratados como corresponde, se reúnan cuanto antes a ellos las pocas familias que por ahora han quedado entendidas de ocurrir a Huajimic a lograr el pasto espiritual. ${ }^{11}$

El 18 de noviembre de 1824 se expidió la Constitución del estado de Jalisco, en donde se estableció su división territorial que comprendía ocho grandes regiones denominadas cantones. El octavo fue el de Colotlán, que quedo como hasta la fecha lo estaba; ningún cambio se realizó en su territorio y se reconoció lo asentado

"l Colección, 1876, t. 1, pp. 25-26. previamente en el "Plan provisional del estado de Jalisco", publicado el 27 de mayo de 1824. En el plan se dice de este departamento:

Colotlán con el Nayarit, y el corregimiento de Bolaños. Este departamento confina por el oeste con los de Acaponeta y Sentispac, por el sur con los de Ahuacatlán y Tequila: por el noreste con el estado de Durango, y por el este y norte con el estado de Zacatecas. Comprende en su territorio el distrito del antigüo partido del mismo nombre, exceptuando todos los pueblos que estén más inmediatos a las capitales de Acaponeta y Sentispac, que a la de este departamento. ${ }^{12}$

\section{El PUEBLO Y la hacIENDA dE CAMOTLÁN DESPUÉS DE LA INDEPENDENCIA}

La guerra de Independencia no duró mucho en la región, sin embargo los estragos fueron considerables. Uno de los más importantes fue la desaparición de poblados enteros, diezma. dos por las epidemias y la desconcentración que durante la guerra se hizo de algunos de ellos. Ya señalamos que en 1822 el comandante de armas de Nayarit pjolió al padre comisario que se realizara un esfuerzo para lograr que los habitantes de Ostoco y Camotlán regresaran a sus pueblos. No sabemos cuánto tardaron en regresar.

En un padrón eclesiástico de 1840 se reporta la población del pueblo de Santo Domingo de Camotlán. Sabemos que por estos años se fundó una nueva congregación huichol, auspi-

12 Colección, 1882-1908. 


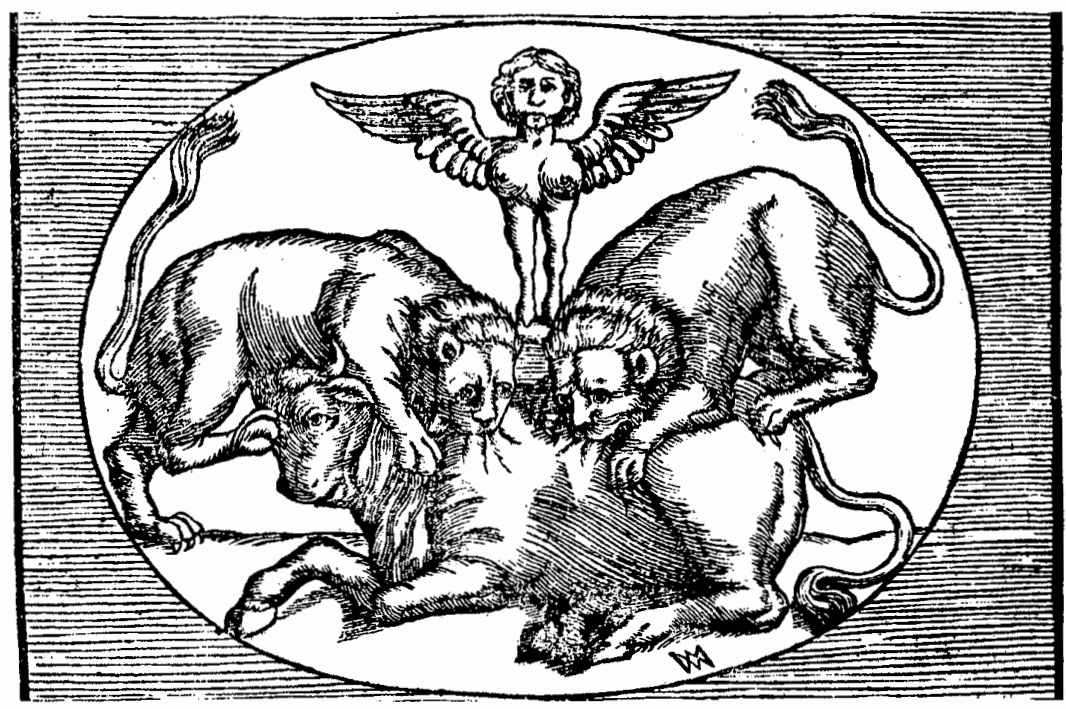

ciada por los padres franciscanos que habian retomado las riendas de la misión de San Sebastián después de casi treinta años de abandono. Nació así el pueblo de Guadalupe Ocotán a finales de los 40, no lejos de Camotlán. El pueblo de Ostoco quedó despoblado por largo tiempo. En $1853 \mathrm{el}$ misionero de San Sebastián informaba que los pobladores de Ostoco, cuyos terrenos habían sido "cedidos a los propietarios [...] y los antiguos poseedores expulsados, se hayan reunido ahora en este pueblo de San Sebastián en donde disfrutan del pequeño terreno que les queda". Cuando se refundó este pueblo allá por 1884 ya no lo hizo en su viejo casco sino en otro de los sitios que también pertenecieron a sus tierras, en el de Tuxpan. ${ }^{13}$

Mientras tanto, el ayuntamiento de Bolaños y el gobierno de Jalisco se confrontaron en la aclaración de un terrible embrollo, surgido de la confusión de iclentidades entre la hacienda y el pueblo de Camotlán. Ya vimos cómo, aprovechando las circunstancias creadas por la guerra de Independencia, la hacienda de Camotlán se echó sobre las tierras del abandonado pueblo del mismo nombre. Después vinieron los problemas entre la señora Pérez y el capitán José Cclcdonio. No volvemos a tener noticias cle

13 "Informes de los padres franciscanos", Archivo Histórico de Zapopan (AHZ) 
este asunto sino hasta 1833 , cuando la hacienda de Camotlán está ya en poder del ayuntamiento de Bolaños.

Sería demasiado largo explicar toda la serie de complicaciones que se fueron presentanclo en este asunto, bástenos señalar que influyó muchísimo la inestabilidad política que caracterizó los primeros decenios de la vida independiente de México y también las leyes de desamortización, que provocaron el reparto en propiedad individual de las tierras comunales de los pueblos indígenas y de las corporaciones. Debido a esto muchas injusticias se produjeron y muchos pucblos, que durante la guerra de Independencia fueron abandonados, vicron sus tierras invadidas y denunciadas como baldías. Cuando se pretendió averiguar qué era el pueblo de Camotlán, y si tenía tierras de comunidad que repartir, se inició una averiguación que sacó a luz la serie de irregularidades suscitadas en torno al pueblo y a la hacienda de Camotlán. $\Lambda$ partir de 1840 se empezó a ventilar este asunto a petición del gobernador del departamento de Jalisco, produciéndose una información que, si no aclara totalmente el embrollo, nos da pistas que permiten presumir lo que sucedió. En uno de estos informes se lee:

Este pueblo fue destruido el año de 1810. Desde entonces quedó abandonado hasta el año de 1825 que renació este mineral y su ayuntamiento recogió sus tierras y las conservó en depósito hasta que don Gerónimo sorier $y$ don Joaquín Cantabrana lo denunciaron. No sabemos el estado de los expedientes; pero éstos no concluyeron. La hacienda de Camotlán y el pueblo del mismo nombre son absolutamente independientes: en la primera está afianzada de una manera sólida la cantidad de $\$ 3060$ que pertenecen al fondo de la escuela por donación de don Miguel de Santiago o don Rosalío Escobar: sus réditos se pagan corrientes anualmente.

Al respecto, la junta departamental expuso en su acuerdo del 9 de enero de 1841 lo siguiente:

Finalmente las ticras del pucblo de Camotlán así como las de Oxtoc, por la existcncia de sus habitantes corresponden al ayuntamicnto o municipalidad de Bolaños, que ha cedido scgún las leyes vigentes en sus derechos, son muy terminantes las que así lo previenen y con arreglo a cllas debe el subprefecto disponer que por el mayordomo de propios sea reconocido Cantabrana o sus herederos por la devolución de las tierras de Camotlán y rentas que adeuda, siguiendo en caso contrario el juicio que corresponde iguales providencias respecto de Oxtoc, teniendo el mismo subprefecto tan luego como dichas tiermas sean sustituidas al fondo; de informar quiénes son los descendientes de aquellos desgraciados que habitaron en otro tiempo esas poblaciones y de cuya solicitud no se tiene conocimiento para tomar las providencias que convenga.

Ya movido el asunto, lo turbio salió a luz y al subprefecto no le quedó sino informar a la junta departamental cómo había sucedido el despojo. En su informe dice: 
Si sobre el pueblo de Camotlán ha sido denunciado al Banco nacional como realengo, por el mismo arrendatario que lo recibió de los fondos hace nueve o diez años. El pueblo de Camotlán, llamado rancho por el mayordomo, en efecto no corresponde si no es en depósito a estos fondos, y fue antiguamente una población lo mismo que $\mathrm{Ox}$ toc (también se dice ser denunciado por un extranjero a quien hace pala un nacional) de indigenas que animados del espíritu de libertad fueron exterminados por el gobierno español: don Celedonio Munguía, dueño de la hacienda de Camotlán, se apoderó de estos terre. nos y luego, en virtud de no sé qué ocurrencia, vinieron como un depósito a esta municipalidad. Don Gerónimo Sorier años después emprendió el denuncio de estos terrenos bajo los auspicios de la ley de colonización: mas don Joaquín Cantabrana lo entorpeció, y luego la posesión de ellos bajo el título que el referido, como atrendatario, pidiéndolos a este ayuntamiento, y como las circunstancias le eran felices, se acordó por dicho cuerpo que una comisión de su seno, previo informe, le impusiera la renta anual que debía pagar: nunca se verificó éste y hasta la fecha su familia lo posee y goza siete años ha la renta que le pagan los arrendatarios. ${ }^{14}$

Llegó el medio siglo y los problemas de la hacienda de Camotlán y la región, seguían sin solución. La finca estaba ocupada por el señor Espiridión Félix y si pagaba alguna renta era una muy corta cantidad que no correspondía al valor de la finca. Ia poca gente que quedaba en el pueblo de Camotlán, tenía que pagar renta

li Colección, 1876, t. I, pp. 259-261. a los arrendatarios o administradores de la hacienda. El viejo pueblo de Ostoco no había aún recuperado sus pobladores; en cambio se estaba consolidando un nuevo poblado en estas se. rranías, el de Guadalupe Ocotán que, para 1854 , contaba ya con 810 habitantes.

\section{APARECE MANUEL LOZADA}

En diciembre de 1848, el misionero de San Sebastián Tezocuautla explica por qué no puede cultivar tierras en esta sierra:

No he dado paso al cultivo de tierras porque todo es barrancoso, al grado de ser necesario andar lo más a pie, y lo segundo, por la ambición de muchos vecinos que aprecian más los $[\ldots]$ de sus ganados que la subsistencia de sus semejantes, aunque para que engorde una cabra sea necesario quitar el alimento al niño que llora de hambre; $y$ al ver a estos miserables sin seguridad en sus terrenos que de tiempo inmemorial, temo me los arrebaten con el auxilio del favoritismo luego que los vean luego con capacidad de cultivarse por lo que si no me asegura el terteno quizá será necesario desistir de la empresa.

[...] Por ta inseguridad del terreno sin duda no podré afirnar las reunio. nes comenzadas, pues, de becho no ha faltado hacendado que les haya quitado una gran parte de lo que poscían; ¿cómo podrá el misionero recomendar y predicar la guardia de los preceptos divinos a estas gentes idólatras con la oposición sorda y venenosa que le hacen tanto los hombres inmorales que se introducen como pretexto de comer- 
cio como los que les han robado sus terrenos? 15

Ia inestabilidad política nacional no permitía dar solución ni ocuparse de los problemas que vivía esta región, que frente a los problemas que vivía la nación no tenían ninguna importancia en apariencia. Sin embargo, justamente en esta zona se estaba gestando un levantamiento armado popular que no tardaría en convertirse en un problema nacional.

A los pueblos y comunidades de esta parte de la Sierra Madre, sin duda, lo que más les dolía a mediados del siglo XIX, era la política que sobre el reparto de tierras de comunidad se empeñaron en aplicar los liberales y hasta los conservadores, en la creencia de que se beneficiaba así a los pueblos. Afortunadamente, la aplicación de las diferentes leyes dictadas sobre el asunto fue tan confusa, que su ejecución no resultaba fácil $y$, gracias a ello, algunos pueblos lograron conservar para estas fechas sus tierras. Pero la inconformidad ante la política nacional era en muchos casos evidente y, cuando en la sierra de Álica apareció un líder convincente, el grueso de la población se unió a su lucha, transformando y trastornando durante veinte años esta región, naciendo así lo que se ha llamado la "Rebelión lozadista".

Desde finales de 1853 la intranquilidad en la sierra del Nayarit se dejó sen. tir. Se empezó a hablar de un cabecilla que se hacía llamar el licenciado Lozada y al que se le calificó en sus prime-

$$
{ }^{15} \mathrm{AHZ} \text {, s.C. }
$$

ros golpes como un simple bandolero. No tardó el gobierno en darse cuenta que era más que eso.

Sì la gente que siguió a Lozada en su rebelión fue predominantemente de la sierra del Nayarit, indígenas coras sobre todo, no lo fue en exclusiva. También la lucha lozadeña atrajo a los pobladores del cantón de Colotlán. Pueblos enteros siguieron al caudillo quien, desde finales de 1854 , comisionó al cabecilla Ventura García para que sublevara a los pueblos del cañón de Bolaños y se adentrase hasta el distrito de Jerez. A partir de estas fechas, y por largos veinte años, los informes de los ataques de las gavillas lozadistas no dejarán de transmitirse. El territorio acosado se extenderá año con año, hasta el momento en que Lozada estará a punto de entrar en la propia Guadalajara. Pero hay que decir que Lozada no quedó aislado de la contienda nacional; si bien siempre luchó por su causa y en su región impuso su ley, no dudó en unirse por momentos a las contiendas nacionales $y$ en aliarse con quien más le conviniese.

Camotlán, Huajimic, la Yesca, Apozolco, Guadalupe Ocotán, la Sierra Huichol, fueron escenario permanente de la lucha. Esto trajo cambios inusitados; en primer lugar, un movimiento militar continuo, enfrentamientos, escaramuzas. Después, abandono de la región, ausencia de autoridades civiles, caos y el predominio de los rebeldes que, imponiendo su ley, recuperaban las tierras que los pueblos habían perdido. Pasaron así los prime ros años de rebelión, hasta que Lozada se unió al gobierno conservador apoyando él también al imperio de 
Maximiliano, para aceptar finalmente como un hecho el triunfo de los liberales. Hizo un pacto con Juárez, que fue respetado por ambas partes hasta la muerte de éste y que consistió en dejar a Lozada la dirección del ya entonces territorio de Tepic, para mantenerlo en paz, mientras que el gobierno juarista lograba pacificar el resto del país. Después vino la rebelión de la Noria y su fracaso, la muerte inesperada de Juárez y la llegada a la presidencia de Sebastián Lerdo de Tejada. Este último aceptó los reclamos del general Ramón Corona contra Lozada en el sentido de impedir que siguiese al frente del gobierno de lepic, y de lograr que las haciendas y propiedades invadidas por los lozadeños fueran devueltas a sus dueños." 16

16 Meyer, Tierra, 1989-1990, pp. 145-2.54́.
Desde diciembre de $\mathbf{1 8 7 2}$ se iniciaron los preparativos de la campaña contra Lozada, asegurándose el gobierno de que muchos de los jefes lozadeños lo abandonaran, lo que provocó que las fuerzas con que contaba Lozada se fueran desintegrando conforme avanzaba la campaña. El 14 de julio de 1873, Lozada cayó preso en manos de uno de sus antiguos lugartenientes y fue inmediatamente fusilado.

Con la muerte de Manuel Lozada la región quecó pacificada, aunque no completamente tranquila. En el disurito de Colotlán, los pueblos de Azcaltan, Tenzompa y Mamata, que habian aceptado rendirse, siguieron armados y agrupados en cuadrillas de bandoleros. Esta intranquilidad perduró por muchos años más, dando origen a que diferentes pueblos se armaran para defenderse unos de otros.

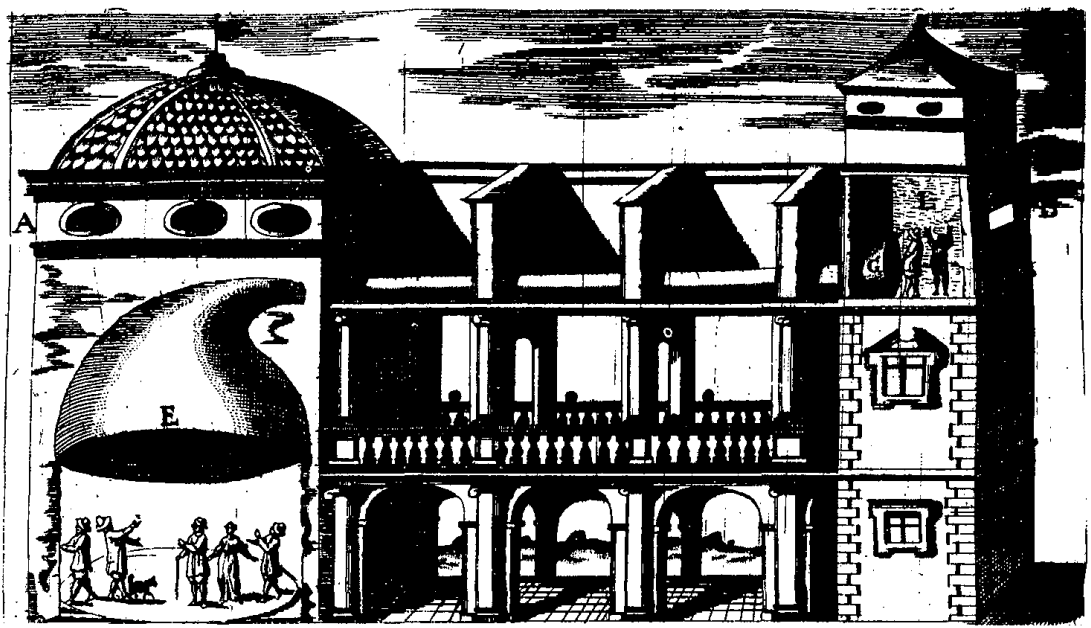


SE CONCEDE A TEPIC EL RANGO DE TERRITORIO

El 8 de diciembre de 1859 el gobierno conservador encabezado por Migucl Miramón, reconociendo los servicios prestados por las fuerzas auxiliares del distrito de Tepic, o sea las fuerzas de Lozada, decretó: "Artículo único: Entre tanto se hace la división territorial de la república, se erije en territorio el distrito de Tepic que conservará los mismos límites que hoy tiene." 17

Al triunfar los liberales no recono. cieron la existencia de este territorio (el 7o cantón del estado de Jalisco), pero hay que decir que Manuel Lozada decidió que Tepic era un estado y en todos sus oficios así lo puso.

El 7 de agosto de 1867, en un acuerdo de gobierno, Juárez decidió formar un distrito militar en Tepic, que dependería directamente del gobierno supremo de la república. Este distrito perduró hasta 1873 , en que se reconquistó y regresó a su antigua jurisdicción civil el territorio dominado por Lozada, con las demarcaciones que correspondían al 70 cantón, pero ya reconocido por el gobierno liberal como territorio, sin ninguna dependencia con Jalisco.

El 31 de octubre de 1868 el jefe político del distrito militar de Tepic envió al ministro de Gobernación una solicitud de los municipios de este distrito, para que se le erigiera en estado de Tepic. El 14 de enero de 1869 el distrito de Tepic fue declarado territorio.

El estado de Jalisco, cargado de

17 lbid., pp. 160-161. problemas, no reaccionó con la debida fuerza a la separación del 70 cantón, por lo que se dio por aceptada su renuncia. De hecho, el control de ese territorio había quedado fuera de su arbitrio descle el inicio del levantamiento de Lozada. Ia zona de Camotán entraba dentro de los dominios lozadistas, es más, parte de sus tierras fueron directamente ocupadas por su gente, explotánclolas y cisfrutándolas como si fueran propias, cosa que hacían en todos los territorios que ocupaban. Al recuperar el gobierno el control sobre estos territorios, el ayuntamiento de Bolaños trató por cuenta propia de recuperar la hacienda de Camotlán. Coincide esto con la refundación del pueblo de Ostoco en 1885, ahora llamado Tuxpan. A partir de ese momento, el territorio de Tepic y el estado de Jalisco iniciaron la querella por sus límites divisorios, quedando el viejo pueblo de Camotlán y la hacienda del mismo nombre entre los terrenos en disputa.

\section{SE INICIA LA CONTIENDA}

Fl 12 de mayo de 1888 los habitantes del pueblo de Guadalupe Ocotán escribieron al gobernador del pueblo de San Andrés Coamiata:

Hace el discurso de cinco años que los vecinos de Huajimic nos han quitado una parte de terreno. El cual nombrado potrero, apropiándose también del terreno llamado Cofradía [...] Y como ambos dos pedacitos conocemos fiel y legalmente que corresponden desde 
tiempo inmemorial a nuestro antiguo pueblo, que reconocemos por cabecera, San Andrés Coamiat [...] también estamos sufriendo muchísimos desaires sin haber ningunos datos para ello. $Y$ por sus abusivas de ellos, ha tenido el gobierno de Tepic que movernos a fin de que quiere que correspondamos a su mando. Siendo que desde tiempo inmemorial hemos correspondido al 8 응 cantón de Jalisco y no a Tepic. ${ }^{18}$

En junio de 1888 el jefe político de Colotlán dijo:

Estoy en la creencia que desde más allá del pueblo de San Juan B. de Camotlán, lo mismo que Ostoco, Santiago de Acaspulco y otros pertenecen al departamento que es a mi cargo, pero como las autoridades de Tepic han dispuesto que aquellos lugares reconozcan como cabecera al mineral de la Yesca, como lo manifesté a usted en et mes de febrero del presente año, me he abstenido de dar ninguna disposición para aquellos lugares, ínterin se ventila dicho asunto con el señor ministro de Gobernación, según usted me lo dispuso. ${ }^{19}$

En este mismo escrito el jefe político señaló:

La revolución que por tanto tiempo sostuvieron por aquellos rumbos Lozada y Rentería destruyeron del todo los pueblos mencionados convirtiéndose en propiedades que cada uno de los que acompañaban a aquellos facinero-

${ }^{18}$ Archivo Histórico de Jalisco (AHJ), G-9-887 CON-3455 C-505.

19 AHJ, G-5-888 BO-3438. sos fue adjudicándose que hasta hoy poseen como si fueran sus legítimos dueños; tal sucede con Palos Colorados, Tlaxcala y otros muchos ranchos que son estancias de la hacienda de Camotlán. Un individuo llamado Mariano García, hermano del famoso Ventura del mismo apellido de fatal memoria por estos lugares, posee la hacienda de Camotlán por la insignificante renta de 35 pesos que anualmente paga, sin que hasta la fecha haya presentado documento ninguno que acredite quién se la haya rentado. 20

El jefe político de Colotlán aconsejó al gobernador de Jalisco la conveniencia de arrendar las tierras de la hacienda de Camotlán para evitar que Tepic las reclame. ${ }^{21}$ Desde agosto de 1890 se suspendió el cobro de contribuciones en la zona de Camotlán, para aclarar a qué estado pertenecia.

El 20 de junio de 1892 los habitantes de Guadalupe Ocotán se quejaron por la medidas que en sus tie. rras han efectuado diferentes ingenieros, desde que el presidente Manuel González en 1884 reconoció el territorio de Tepic. De las medidas que se efectuaron en mayo de 1890 , el gobernador de este pueblo dijo:

Ya desde noviembre de noventa fue invadido el territorio de mi mando por otra compañia de ingenieros que por disposición del $\mathrm{C}$. jefe político de Tepic vinieron a medir. Me limité a dar cuenta al $C$. jefe político del cantón y le acompañé yo a usted la resolución,

20 Ibid.

21 Ibid. 
y en seguida en mayo del año próximo pasado, como también fuimos invadidos por una compañía de ingenieros que conducia el señor hacendado de Camotlán, nos quitaron más de diez sitios de ganado mayor, a los que a la desta [vez] ya está reconociendo la dicha hacienda. ${ }^{22}$

En 1905 el ayuntamiento de Colotlán dice que no ha podido intervenir en Camotlán porque no tiene autoridades; que Mariano García es autoridad puesta por Amatlán de Jora del territorio de Tepic y que este mismo se encarga, a nombre del gobierno de Tepic, de arrendar las tierras de $\mathrm{Ca}$ motlán. Por orden del gobernador de Jalisco en 1906 se forma un amplio expediente sobre la pertenencia de la hacienda de Camotlán a este estado. Algunos documentos ya se habían empezado a recabar desde 1895.

El 7 de noviembre de 1908 el gobernador del pueblo de Tuxpan se queja por las medidas que se quieren efectuar en las tierras de su pueblo:

C. gobernador del estado de Jalisco, pongo en conocimiento de usted, que han llegado unos americanos diciendo que traían órdenes de usted para medir el terreno de la comunidad de los huicholes y yo no permití la medida hasta el interin hablar con usted, porque según mi juicio creo no es necesario el que midan nuestras propiedades por que estamos lejos de Camotlán y estos señores quieren meterse a la mitad de mi terreno a un cerro que se nombra el Saucillo, queda como a tres leguas lejos de

22 AHJ, G-9-892 Con-3477.
Camotlán y por lo mismo le suplicamos la comunidad de huicholes, nos dé una orden para que no midan. ${ }^{23}$

En marzo de 1909, los vecinos de lo que llaman el cuartel de Puente de Camotlán solicitan a las autoridades de Bolaños se les erija en comisaría política y se les dé una oficina de registro civil, señalando que esta comisaría quedaría compuesta por los ranchos siguientes: el Portezuelo, los Nogales, la Mesa, la Laguna, la Soledad, Pescadores y otros pequeños ranchos cuya población cuenta al dia 1225 habitantes. La respuesta no les llegó sino dos años y medio después, cuando el gobernador interino del estado de Jalisco, Alberto Robles Gil, concedió la comisaría a Puente de Camotlán. ${ }^{24}$

E1 8 de diciembre de 1909 nuevamente el gobernador de Tuxpan se queja ante el gobernador del estado de Jalisco porque al embargar tierras de la hacienda de Camotlán se embargaron también tierras de su pueblo. En su escrito dice así:

Recientemente el empleado de Rentas de Chimaltitán ha mandado embargar terrenos de la hacienda de Camotlán de este municipio dizque por adeudo de particulares, informé detenidamente con las personas que presenciaron tal diligencia con el objeto de saber si no se habían extralimitado hasta los terrenos de $\mathrm{mi}$ pueblo, puesto que colinda con la referida hacienda de Camotlán y he venido a comprobar que el agente fiscal indebidamente embargó también

\footnotetext{
23 AHJ, G.9-908 C. -516.
}

24 AHJ, G-909 BO-3460. 
terrenos de mì comprension, como es el muy antiguo pueblo de Ostoque y donde anteriormente residía la cabeza de este pueblo de Tuxpan. ${ }^{25}$

\section{LLEGA LA REVOLUCIÓN}

Muchos pueblos de la sierra se unieron a la revolución. Cada quien escogió el bando que más le convino. Es difícil explicar por qué unos se fueron con un bando y otros con otro. San Andrés se fue con los carrancistas, San Sebastián y Apozolco con los villistas. Muchas veces jugaron pleitos regionales internos para definir la actitud que tomaría cada pueblo en su pertenencia partidista. Pero en esta parte de la Sierra Madre se puede decir que dominó el villismo y que los constitucionalistas tardaron en acabar con sus opositores. El resultado de esta confrontación fue una guerra dura y sin cuartel durante varios años.

Con la revolución la región de $\mathrm{Ca}$ motlán volvió a ser centro de luchas partidistas y el gobierno de Jalisco perdió nuevamente el control que con grandes esfuerzos había tratado de recuperar. El que Jalisco haya concedido en 1911 la comisaria y el registro civil, que desde hacia unos años pidieron los de Puente de Camotlán, puede significar un intento más de Jalisco para seguir controlando esta región. Con esta medida se reconoció la existencia de este poblado, dando así origen a tres Camotlanes: el viejo pueblo, la hacienda y esta nueva congregación, formada muy posiblemente por arrenda-

$$
{ }^{25} \text { AHI, G-9-909 C-501. }
$$

tarios de la hacienda o por simples posesionados instalados en las tierras de esta propiedad.

Uno de los sucesos viviclos durante este periodo fue que la Constitución de 1917 concedió la categoría de estado al territorio de Tepic. El conflicto por límites con este reconocimiento todavía no se hacia patente. Por el momento aparentemente no hubo reclamos y se quedaron las cosas como estaban, respetando el estado de cosas. En 1906 ya había levantado el gobierno de Jalisco un expediente sobre la pertenencia de este territorio. Pero cuando este expediente se formó, lo que más bien parecía disputarse no era el que Camotlán perteneciera a Jalisco o a $\mathrm{Na}$. yarit, sino el que la hacienda de Camotlán perteneciera al ayuntamiento de Bolaños. La disputa entre los dos estados tardó todavía algunos años en aparecer.

No fue sino hasta que regresó la calma cuando surgió nuevamente el problema por la posesión de las tie. rras de la hacienda de Camotlán, las cuales, esta vez, curiosamente, eran disputadas por varios interesados. Por un lado, estaba el reclamo del ayuntamiento de Bolaños, por otro, el de una compañía que se denominaba Camotlán y Anexas S. A., cuyo representante, Francisco Sordo Pedregal, envió un oficio en enero de 1920 , desde la ciudad de México, a la Secrecaría de Agricultura y Fomento. El texio decía que, como representante de la Compañia Camotlán y Anexas S.A., dueña de las haciendas de Camotlán y de la Manga, comunicaba a ese gobierno los planes que tenía para fraccionar y colonizar estas propieda- 
des; que esto no lo habían realizado antes porque la situación política del país no se lo había permitido, pero que ahora que la paz parecía reinar se les presentaban otros impedimentos, porque estas tierras se encontraban invadidas por extraños que no querían desalojarlas; que su compañía pensaba, al realizar el fraccionamiento, dar facilidades para que estas personas adquiriesen las parcelas que ocupaban, pero que necesitaban la cooperación del gobierno para lograr realizar sus planes.

La Secretaría envió el expediente al presidente municipal de Bolaños pidiéndole su cooperación, ya que él tenía influencia sobre los huicholes como para lograr que desalojaran las tierras de esta compañía. ${ }^{26}$

¿Por qué esta compañía se decía dueña de esas tierras? No lo sabemos. ¿Tendría esto que ver con los levantamientos y planos realizados durante el porfiriato por las compañías deslindadoras o con el pleito que entabló el ayuntamiento de Bolaños con el general Carlos Díez Gutiérrez, gobernador porfirista de San Luis Potosí?

Sus reclamos no deben haber dado fruto ya que, meses después, en 1921, encontramos, al ayuntamiento de Bolaños arrendando a diferentes personas ranchos, estancias y bosques de la hacienda de Camotlán. Destaca el efectuado a la Compañía minera El Tajo, que pagaría 1800 pesos anuales para poder explotar los bosques de esta hacienda. Ese mismo año, el ayuntamiento levantó una información ad perpetuam para probar que, desde fe- chas lejanas, era el dueño de la hacienda de Camotlán. En ella interroga a unas diez personas y todas testifican en favor del ayuntamiento. ${ }^{27}$

\section{LA REFORMA AGRARIA}

Con la revolución llegó la reforma agraria y, en cierto sentido, la posibilidad para los pueblos de hacer tabla rasa y recuperar las tierras perdidas. Pero en nuestra región ecuál era la situación y qué iban a pedir los pueblos?

Aparte del conflicto existente por la posesión de la hacienda de $\mathrm{Ca}$ motlán, reclamada por un sinnúmero de dueños, existían una multitud de viejos conflictos producidos, como en todo el país, por la sobreposición de una serie de medidas desamortizadoras que, por lo complicado en su ejecución, no habían dejado sino expedientes inconclusos, descontrol y enojo en los interesados, ya fuesen los dueños de los bienes desamortizados o los nuevos denunciantes.

Mientras duró la violencia en la sierra la reforma agraria no llegó o hizo una aparición velada. ¿Para qué apelar a la ley si en estos momentos la ley la hacía la fuerza? Además, la violencia en esta zona se prolongó y siguió con el levantamiento cristero. Cuando la reforma agraria llegó, corrían ya los años treinta.

Como se ve en el cuadro que sigue, las solicitudes fueron tardías y las resoluciones llevaron también años en darse. El asunto de Camotlán, siempre

27 AHJ, G-5-934 BO-3794. 


\section{Peticionario}

San Andrés Coamiata

Guadalupe Ocotán

anexo de S. Andrés

San Sebastián

Tuxpan de Bolaños

Puente de Camotlán

Huajimic

Santa Catarina
Solicitud

25-XI-38

25-XI-34

26-III-35

6-IV-38

7-v-46
Resolución

14-IX-1965

15-VII-1953

2-iX-1947

12-XII-1951

1961

9-VIII-1960
Restitución

74940

240447

53650

24755 vigente, se vino a complicar con los reclamos que por sus tierras promovieron los huicholes de los pueblos de San Sebastián Teponahuastlán y Tuxpan de Bolaños, que reclamaban como suyas gran parte de las tierras de esta hacienda.

La situción no era fácil, por eso tardarían tanto en llegar las resoluciones. Pero, cuando llegaron, fueron positivas para los pueblos huicholes, ya que se les reconocieron las tierras que llevaban decenios reclamando.

LOS HABITANTES DE HUAJIMIC, COLONOS EN CAMOTLÁN

El pueblo de Huajimic fue una fundación franciscana de los primeros años del siglo XVI, allí se congregaron indígenas de la sierra, sobre todo los huicholes, que aceptaron vivir bajo la tutela de los misioneros.

Poco a poco esta región se fue poblando por gente que venía de fuera, sobre todo cuando habia algún descu. brimiento minero, como sucedió con Jora y la Yesca. Estos nuevos habitantes fueron ocupando paulatinamente las tierras a los pueblos indígenas de esta región y empezaron a pedir mercedes de tierras. En el censo que mandó levantar la curia de Guadalajara, a finales del siglo Xvil, ya se ve con claridad cómo los indígenas quedaron en desventaja frente a españoles y castas. Las peticiones de mercedes presentadas por estos nuevos pobladores se iniciaron desde principios de siglo. Pronto Huajimic dejo de ser un pueblo indígena para convertirse en mestizo. Su población creció más rápidamente que la de Camotlán y sus habitantes empezaron a colonizar las tierras. La expansión de Huajimic continuó hasta el siglo $\mathrm{Xx}$.

El que la colonización de Camotlán la hiciera gente de Huajimic facilitó que se consideraran estas tierras de Nayarit y no de Jalisco. Además, como eran los directamente beneficiados, no estaban dispuestos a abandonar las tierras del Cañón de Camotlán. Cuando el municipio de la Yesca empezó a cobrar contribuciones y arriendos a la gente asentada en Camotlán, ésta no dudó ni un momento en fomentar la decisión de Nayarit de hacer suya la región de Camotlán.

Cuando Jalisco decidió reclamar, Camotlán ya estaba en manos de los 
nayaritas y esto en cierta medida era irreversible. Para empezar, Nayarit te. nía allí a gente dispuesta a realizar un sinnúmero de atropellos por conservar esas tierras. Es el caso de Petronilo Muñoz que desde 1923 fue acusado por los huicholes de Guadalupe Ocotán y San Andrés de meterse en sus tierras. Muñoz encabezó durante más de 35 años las invasiones. Era vecino de Huajimic y durante muchos años fue agente de la policia judicial de Nayarit. Fue asesinado en la sierra en 1959. Dicen que un huichol de Tuxpan le dijo a uno de los invasores de Huajimic: "Ahora sí ya se te acabo tu rey, Petronilo."

\section{LOS HUICHOLES QUIEREN PERTENECER A JALISCO}

Los huicholes siempre pertenecieron al distrito de Colotlán y, cuando se empezaron a presentar los conflictos, no dudaron en reiterar su pertenencia y así lo hicieron saber en muchas ocasiones. Recordemos lo que dijo un agente colonial allá por 1802 , cuando se pretendió reorganizar este gobierno, afirmando que los pueblos que pertenecían a Colotlán se negarían a pertenecer a otro distrito, o cuando en 1888 los habitantes de Guadalupe Ocotán mandaron decir al gobernador de Jalisco sus quejas sobre los de Huajimic y su negativa a pertenecer a ese territorio, porque "desde tiempo inmemorial hemos correspondido al $8^{\circ}$ Cantón de Jalisco y no a Tepic".

Esta negativa șe repetiría periódicamente. En marzo de 1935, los del pueblo de Tuxpan dicen que no quieren pertenecer al estado de Nayarit $y$, por lo tanto, envían al gobernador de Jalisco sus representantes para

tratarle algunos asuntos relacionados a sus propios intereses, principalmente el que se refiere a la inconformidad que tienen para pertenecer al estado de $\mathrm{Na}$ yarit, pues con mucha insistencia les han dicho algunos elementos de Nayarit que próximamente pertenecerán a su estado. Pues que el diputado Leocadio Quintanilla les ha ofrecido a sus representantes por el distrito de la Yesca, que ya está próximo el deslinde de la línea divisioria y que, según los linderos aprobados, según ellos por el C. gobernador de su propio estado, queda una porcion de terreno de este estado de Jalisco adherida al de Nayarit. ${ }^{28}$

\section{CRONOLOGIA DE LAS NEGOCIACIONES ENTRE JALISCO Y NAYARTT}

En marzo de 1936 hay rumores de que los gobernadores de Jalisco y Nayarit llegarán pronto a un acuerdo sobre colindancias.

El 8 de julio de 1939 la oficina de catastro de Jalisco dice que la hacienda de Camotlán siempre ha pertenecido a Jalisco y que no hay tratos con Nayarit para llegar a un acuerdo.

En diciembre de 1940 el gobierno de Jalisco envió a Colotlán un visitador de Hacienda para que informara de la situación catastral de este distrito. Sobre Camotlán el visitador dijo que los límites con Nayarit son inciertos; que acababa de medir los terrenos de los huicholes una comisión enviada de México.

${ }^{28} \mathrm{AHJ}$, G.5.933 BO-3795. 
El 16 de febrero de 1945 los gobernadores de Jalisco, general Marcelino García Barragán, y el de Nayarit, Candelario Miramontes, crearon una comisión de estudios sobre los problemas de Puente de Camotlán

para que con la vista del material de ambas comisiones y de los elementos que pudieren allegarse en el territorio referido, practicaran las operaciones necesarias para determinar la localización de los poblados denominados hacienda de Camotlán, El Puente o Puente de Camotlán y el pueblo de Camotlán, señalando la situación de los mismos en relación con una y otra de las dos entidades federativas, apreciando $y$ detallando sus relaciones de proximidad y de conexión con las poblaciones de la Yesca, Apozolco y Bolaños y estudiando y elaborando su información a efecto de que los gobiemos estén en condiciones de definir y legalizar en forma definitiva los linderos de los dos estados en la zona cuya situación y correspondencia se hallan actualmente en estado de confusion. ${ }^{29}$

En marzo de 1946 el gobierno de Jalisco nombró al señor Francisco $M$. del Campo para que tramitara con el gobierno de Nayarit la devolución de la hacienda de Camotlán.

La resolución presidencial de San Sebastián, 15 de julio de 1953 , reconoce 240447 hectáreas que abarcan parte de la hacienda de Camotlán.

El 3 de febrero de 1954, el jefe de la policía judicial de Huajimic envió un informe al procurador gene244

29 Gutiérrez Contreras, Territorio, 1979, p. ral de Justicia de Nayarit, en donde le informó cómo los huicholes se han apoderado violentamente de varios predios en la zona de Camotlán. En este mismo informe se lee:

Hay que hacer notar al respecto que los indígenas de los antes dichos ranchos han sido incitados al despojo por un individuo de nombre Pedro Haro que es quien los capitanea, pasando el citado falso indígena ante otras autoridades, como si fuera de verdad huichol.

Más adelante añade que "los huicholes han asumido una actitud rebelde por lo que se esperan choques sangrientos." 30

El 11 de noviembre de 1956 los habitantes de Huajimic dicen que los de Guadalupe Ocotán invaden sus tierras y dan su versión sobre la fundación de Guadalupe Ocotán diciendo que, en 1822 , se les permitió asentarse en tierras de Huajimic y se les concedieron 40000 hectáreas; que descle entonces hasta 1936 vivieron pacíficamente pero que, a partir de este año, se aliaron con los de San Andrés y ahora reclaman más tierras.

E1 9 de julio de 1959 los habitantes de Nayarit pretenden delimitar sus colindancias con Jalisco, los huicholes se oponen y colocan estacas hasta donde ellos consideran que llegan sus tierras y los límites de Jalisco. Seis días después muere asesinado Petronilo Muñoz.

El 13 de abril de 1975 se informa que Tuxpan y San Sebastián cobran

30 Sala Regional del Cuerpo Consultivo Agrario (ASRCCA), Exp. de Huajimic. 


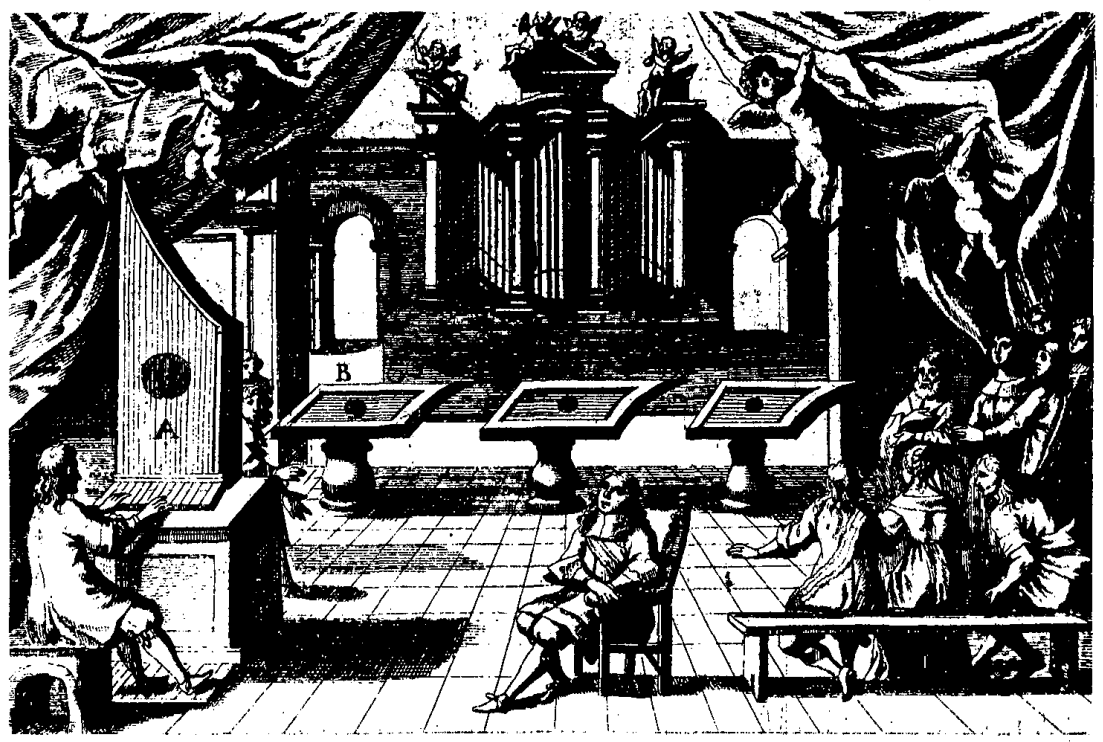

renta a los habitantes de la hacienda de Camotlán por dejar pastar allí a sus ganados, no obstante tratarse de tierras nacionales. En la resolución presidencial de San Sebastián se le confirmaron terrenos de la hacienda de Camotlán. ${ }^{31}$

El 28 de febrero de 1975 la Secretaría de la Reforma Agraria comisiona a un técnico conciliador para que en Puente de Camotlán confronte los problemas entre este pueblo y los de San Sebastián. Puente de Camotlán solicitó ejidos el 6 de abril de 1938, pero su expediente tardó mucho en tramitarse. Tuxpan,por su parte, solicita en

31 Archivo Secretaría de la Reforma Agraria (ASRA), s.C. marzo de 1935 la confirmación y titulación de sus bienes comunales. Pretende 310350 hectáreas, pero tan sólo se le confirman 53650 por resolución presidencial del 9 de julio de 1947.

El 20 de abril de 1977, el vocal del centro coordinador para el desarrollo de la zona huichol solicita la intervención de la Secretaría de la Reforma Agraria para solucionar los problemas que confrontan a los comuneros de Tuxpan de Bolaños y a los ejidatarios del pueblo de Puente de Camotlán.

E1 20 de octubre de 1980 la comunidad de San Sebastián conviene con los ganaderos que, con fecha de 1979, le paguen una renta por cada cabeza de ganado que paste en sus tierras. 
El 31 de julio de 1990 el secretario general de gobierno de Nayarit, Pedro Ponce de Ieón, declara que Puente de Camotlán pertenece a Nayarit. El estado se quejó por las incursiones de policias de Jalisco en su territorio. ${ }^{32}$

E1 2 de agosto de 1990, por seguir pendiente la delimitación de colindancias entre Jalisco y Nayarit, los gobernadores de ambos estados piden a la Secretaría de Gobernación su mediación.

\section{LOS ALEGATOS DE NAYARTT}

No tengo noticia de ningún documento que señale los alegatos que Nayarit ha presentado para comprobar los derechos que tiene sobre $\mathrm{Ca}$ motlán. En cambio, existe un trabajo del historiador nayarita Salvador Gutiérrez Contreras, publicado en 1979 , que contiene los elementos del alegato que este estado podría presentar.

Para no tocar todos los puntos que don Salvador señaló, y que a mi ver se reducen en uno solo, resumiré: conforme a la división territorial del 27 de marzo de 1823 el territorio del estado de Jalisco quedó subdividido en 26 departamentos. Uno de ellos era el de Ahuacatlán, que comprendía a su vez el de la comprensión del Real de la Yesca, que abarcaba el pueblo de Camotlán. ${ }^{33}$

¿De donde obtuvo la información de que Camotlán pertenecía a la Yesca?

32 El Nacional, 1 de agosto de 1990.

33 Gutiérrez Contreras, Territorio, 1979, p. 45; Colección, 1876, t. I, pp. 25-26.
Según nuestro autor la tomó de la Estadística del estado de Jalisco, publicada por Victoriano Roa, quien elaboró su texto a partir de una serie informativa mandada levantar en 1822 por la diputación provincial de Guadalajara. En esta estadística, publicada recientemente por el gobierno de Jalisco, se lee en la página 129: "A Amatlán de Jora, situado en un plan a su ayuntamiento, están sujetos los pueblos de Huaximic, otro Camotlán y el Real de Yesca."

¿Por qué dice "otro Camotlán"? Porque en el departamento de Ahuacatlán existía otro.

En la misma página 129 , cuando enumeran las haciendas y ranchos de este departamento, se lee: "En el de Amatlán de Jora, las haciendas de San Blas, Comaltitán, la Labor, Cofradía y Quesería con 5 ranchos."

Aquí no aparece, como debiera, la hacienda de Camotlán, ni otras que sabemos existían en este distrito. Pero prosigamos. En la página 146 de este trabajo, cuando se enumeran las haciendas existentes en el $8^{\circ}$ cantón de Colotlán, el autor señala: "En el distrito del ayuntamiento de la capital existen 27 ranchos [...] En el de Bolaños, las haciendas de Camotlán, Tule y seis ranchos."

O sea que, en esta estadística, Victoriano Roa concede al $7 \underline{0}$ cantón de Tepic el pueblo de Camotlán, y al 80 cantón de Colotlán la hacienda del mismo nombre, como si fueran dos cosas diferentes.

Sabemos por otra información, como el oficio del 27 de marzo de 1822 girado por el teniente Ramón Vargas al presidente de las misiones del Nayarit, 
que "tenga muy presente atender del mismo modo en este punto a los pueblos de Ostoco y Camotlán del gobierno de Colotlán." 34

Como se ve, este oficio contradice lo señalado por Victoriano Roa. He tenido cuidado en revisar todos los decretos que Salvador Gutiérrez Contreras enumera para validar la pertenencia de Camotlán a Nayarit y no encontré la inclusión de Camotlán en Nayarit, sino la Estadística de Victoriano Roa, y una serie de mapas cuya información procede de esta misma fuente.

\section{¿QUÉ DICE LA CARTOGRAFÍA?}

La que consulté es por demás contradictoria. La del siglo XIX es deficiente por razones técnicas y la del $\mathrm{xX}$ por motivos políticos. Hay que destacar entre los mapas que de esta región existen, los elaborados por Narváez, militar de la marina española. Estos mapas son de los primeros levantados después de la guerra de Independencia. A él debemos un mapa del estado de Jalisco de 1824, en donde Camotlán aparece en ese momento formando parte del distrito de Tepic.

Otra carta geográfica que debemos señalar y tomar en cuenta es la elaborada por Orozco y Berra, ya que, durante muchos decenios, fue la mejor representación geográfica del país y de los estados. La de Jalisco, publicada en 1867, tiene los mismos defectos que otras y su consulta no nos ayuda a esclarecer el problema ya que Camotlán

34 Colección, 1876, t. I, pp. 25-26. ni tan siquiera aparece. En los otros mapas consultados, depende del autor y del patrocinador el lado en que se sitúa Camotlán, ya sea del lado nayarita o jalisciense. En muchos casos para no comprometerse se deja el espacio en blanco, sin nombres y sin linderos.

\section{CONCLUSIÓN, SI ES QUE PUEDE HABERLA}

¿Qué se puede concluir de este largo texto y de varios meses de rastrear este asunto? No pretendo dar solución al conflicto existente entre estos dos estados, sino tan sólo presentar una serie de elementos que nos permitan conocer cómo surgió y los cauces que ha seguido.

Dos factores fueron la razón directa para que el conflicto se presentara. Primero, el problema que surgió en torno al pueblo y a la hacienda de Camotlán. La confusión entre estas entidades provocó una primera dificultad entre el estado de Jalisco y el entonces territorio de Tepic, ya que las tierras de la hacienda estaban efectivamente asentadas entre Colotlán y Huajimic. Para certificar esto hay que ver dónde se concedieron las primeras mercedes a la hacienda de Quelita, en el siglo XVIII.

Por otro lado, Camotlán, el pueblo, perteneció sin réplica al estado de Jalisco hasta finales del siglo XIX. La confusión surgió cuando por la rebelión lozadista el gobierno se vio obligado a constituir un distrito militar en el territorio rebelde, que permitiera una mejor comandancia de las fuerzas armadas gubernamenta- 
les. Así, momentáneamente, Camotlán formó parte del gobierno militar de Nayarit. Cuando la rebelión lozadista fue controlada, este gobierno militar desapareció y fueron reintegrados a sus jurisdicciones civiles cada uno de los distritos que había sido necesario incluir en la comandancia militar. Guazamota regresó a Durango y Camotlán debió haber regresado a Colotlán, Jalisco. Pero esto sucedió sólo a medias porque, como ya vimos, las tierras del pueblo y de la hacienda de Camotlán se poblaron con gente de Huajimic y de la Yesca que, por conveniencia y costumbre, no estuvieron dispuestos a reconocer que Camotlán pertenecía a Jalisco. A partir de entonces el problema surgió y, hasta la fecha, no encuentra solución. Cada vez se complica más.

No creo que sea con fundamentos históricos que se resuelvan este tipo de problemas. Mas aunque obedezcan a causas históricas, llega un momento en que lo que debiera privar en la solución de estos problemas sería el interés y la paz pública, o sea la razón política.

\section{BiBLIOGRAFÍA}

-Colección de acuerdos de los indigenas del estado de Jalisco, 2a. ed. aumentada, 5 vols., tipografia de S. Banda, Guadalajara, 1876.

-Colección de decretos, circulares $y$ órdenes de los poderes legislativo y ejecutivo del estado de Jalisco, Unión Editorial, Guadalajara, 1882-1908.

-Gerhard, Peter, The nortb frontier of New Spain, Princeton University Press, Princeton, 1982.

-Gutiérrez Contreras, Salvador, El territorio del estado de Nayarit a través de su bistoria (Ed. del autor), Compostela, $\mathrm{Na}$ yarit, 1979.

-López, Eucario, Algunos documentos de Nayarit, Librería Font, Guadalajara, 1978.

-López, Juan, La insurgencia de la Nueva Galicia en algunos documentos, $t$. Il, Ayuntamiento de Guadalajara, Guadalajara, 1984.

-Meyer, Jean, Colección de documentos para la bistoria de Nayarit, CEMCAUniversidad de Guadalajara, México, 19891990,5 vols.

, La tierra de Manuel Lozada, CEMCA, México, 1989.

-Muría, José Mariá, Historia de las divisiones territoriales de Jalisco, INAH, México, 1976 (Colección científica, 34).

-Roa, Victoriano, Estadística. Estado libre de Jalisco, UNED, Guadalajara, 1981.

- Tello, Antonio, Crónica miscelánea de la sancta provincia de Xalisco, Gobierno del estado de Jalisco, Guadalajara, 1984 .

-Valdés Huerta, Nicolás, Bolaños, Jal., Ediciones Espiral, Guadalajara, 1979.

-Velázquez, María del Carmen, Colotlán. Doble fiontera contra los bárbaros, UNAM, México, 1961. 